\title{
Molecular and neurocircuitry mechanisms of social avoidance
}

\author{
Anne-Kathrin Gellner ${ }^{2} \cdot$ Jella Voelter ${ }^{3} \cdot$ Ulrike Schmidt $^{2,5} \cdot$ Eva Carolina Beins $^{6} \cdot$ Valentin Stein $^{7}$. \\ Alexandra Philipsen ${ }^{2} \cdot$ René Hurlemann ${ }^{1,3,4} \mathbb{C}$
}

Received: 30 May 2020 / Revised: 9 September 2020 / Accepted: 15 September 2020 / Published online: 30 September 2020

(c) Springer Nature Switzerland AG 2020

\begin{abstract}
Humans and animals live in social relationships shaped by actions of approach and avoidance. Both are crucial for normal physical and mental development, survival, and well-being. Active withdrawal from social interaction is often induced by the perception of threat or unpleasant social experience and relies on adaptive mechanisms within neuronal networks associated with social behavior. In case of confrontation with overly strong or persistent stressors and/or dispositions of the affected individual, maladaptive processes in the neuronal circuitries and its associated transmitters and modulators lead to pathological social avoidance. This review focuses on active, fear-driven social avoidance, affected circuits within the mesocorticolimbic system and associated regions and a selection of molecular modulators that promise translational potential. A comprehensive review of human research in this field is followed by a reflection on animal studies that offer a broader and often more detailed range of analytical methodologies. Finally, we take a critical look at challenges that could be addressed in future translational research on fear-driven social avoidance.
\end{abstract}

Keywords Social avoidance $\cdot$ Social anxiety $\cdot$ Neuronal circuits $\cdot$ Modulators of behavior $\cdot$ Translational models

\section{Introduction}

From an evolutionary perspective, the social environment is not only crucial for survival and reproductive success but substantially shapes physical and mental health [1]. Under

René Hurlemann

rene.hurlemann@uol.de

1 Division of Medical Psychology, Department of Psychiatry, University Hospital, Venusberg-Campus 1, 53127 Bonn, Germany

2 Department of Psychiatry and Psychotherapy, University Hospital Bonn, Venusberg-Campus 1, 53127 Bonn, Germany

3 Department of Psychiatry, School of Medicine and Health Sciences, University of Oldenburg, Hermann-Ehlers-Str. 7, 26160 Bad Zwischenahn, Germany

4 Research Center Neurosensory Science, University of Oldenburg, 26129 Oldenburg, Germany

5 Department of Psychiatry Und Psychotherapy, University of Göttingen, Von-Siebold-Str. 5, 37075 Göttingen, Germany

6 Institute of Human Genetics, University Hospital Bonn, Venusberg-Campus 1, 53127 Bonn, Germany

7 Institute of Physiology II, University Hospital Bonn, 53115 Bonn, Germany certain circumstances and in response to environmental cues, social species including humans can deviate from their social nature and avoid social contact. Such behavior includes healthy as well as pathological manifestations. In animals, social avoidance can function as a survival technique or is part of submissive behavior, often provoked by social threat, e.g. an intruding dominant conspecific. In humans, social avoidance is often expressed as a behavioral symptom of anxiety, aiming at the avoidance of feared social evaluation and related negative emotions. Many psychiatric disorders are characterized by prominent interpersonal problems, including exaggerated social avoidance and aberrant control of approach-avoidance actions. Therefore, translational efforts have been made to better understand the molecular and neural network mechanisms underlying social approach-avoidance behavior to combat diseases that are marked by social avoidance. In this regard, animal research is instrumental in deciphering the molecular and neuronal underpinnings of social avoidance and for identifying new targets for potential neurobehavioral and pharmacological treatments. In the present paper, we present an overview of the molecular and neurocircuitry mechanisms underlying social avoidance. First, we focus on experimental work in humans and afterward on animal models. Hereby, we cover 
a broad spectrum from research on healthy to pathological social avoidance, including neural mechanisms and the influence of various modulators on social avoidance behavior. We conclude this review by discussing challenges and suggesting improvements for translational research on social avoidance in future studies.

\section{Social avoidance in the healthy human model}

Social avoidance is a physiological and sometimes even lifesaving facet of human behavior that is accompanied by aversive emotions and thoughts upon expecting or experiencing social situations. It can therefore function as a safety behavior that prevents or alleviates feelings of shame and anxiety [2]. In experimental settings, social avoidance is mainly assessed as an instinctive, automatic response to social threat, which is fear-driven or part of subordinate behavior. Within this framework, avoidant responses are modulated by subjects' level of anxiety and by previous episodes of social stress. To examine the sub-clinical range of social avoidance, questionnaires are used to classify healthy subjects into high-anxious vs. low-anxious. Social avoidance is often not assessed separately but as part of self-report questionnaires targeting social anxiety, e.g. the Liebowitz Social Anxiety Scale (LSAS-SR) [3]. However, self-assessments are prone to distortions, e.g. as a consequence of subjective self-awareness, along with a tendency to select socially accepted answers. Given the aforementioned limitations, the focus here lies on the behavioral probes of social avoidance, some of which can also be used for neuroimaging studies, including functional MRI (fMRI). Several paradigms have been devised to map social avoidance as well as its opposite, approach behavior. Among these, the Approach-Avoidance Task (AAT) is one of the most frequently used. Specifically, participants approach positive social stimuli (happy faces) or avoid negative social ones (angry or fearful faces) by pushing a button or moving a joystick towards or away from themselves. Often, the AAT is subdivided into two conditions: an affect-congruent condition, in which participants approach positive stimuli and avoid negative stimuli, and an affect-incongruent condition requiring the opposite, i.e. to approach negative stimuli and avoid positive stimuli [4-6]. This subdivision makes it possible to also assess the control of social approach-avoidance behavior which can be dysfunctional in psychiatric disorders [6]. Affect-congruent responses result in faster reaction times than affectincongruent ones, described as the congruency effect $[6$, 7]. High-anxious participants however tend to avoid both happy and angry faces, most likely because any of these express some form of feared social interaction $[8,9]$. While the AAT tests basic approach-avoidance tendencies, these tendencies may be more pronounced under conditions of socially evaluative stress in which compensatory mechanisms become insufficient.

To investigate the interference of socially evaluative stress with approach-avoidance, the Trier Social Stress Test (TSST), a laboratory stress experiment usually performed outside the fMRI scanner, is used in combination with other tasks such as the AAT to create a naturalistic, stressful and socially-threatening situation $[5,10]$. The TSST consists of a mock job interview, including a free speech and the performance of mental arithmetic tasks in front of an application committee, where committee members constantly maintain a neutral facial expression [11-13]. A significant increase in cortisol levels has confirmed the TSST's ability to provoke psychosocial stress $[13,14]$. To examine the direct effects of increased psychosocial stress inside the fMRI scanner as done by Lederbogen et al. [15], the Montreal Imaging Stress Task (MIST) was developed. Similarly to the TSST, the MIST consists of a computer-based mental arithmetic task and includes a social evaluative threat component [16].

There have been various experimental attempts to quantify the magnitude of social avoidance. One such study was performed by Schultz et al. [17]. Specifically, the authors devised an fMRI choice task, where participants had to choose between a risky and a safe option to win money. When choosing the safe option, participants received a predetermined fixed amount of money. The outcome of the risky option, which resulted in a game of dice against a human partner and therefore in social interaction, varied between either zero or three euros. The authors measured how often participants engaged in an uncertain social interaction as opposed to choosing the safe option of making money. At the behavioral level, the task thus allows to estimate the monetary costs that social avoidance comes within social contexts. On the neural level, the task maps decisionmaking related processes and responses to social feedback as a function of subjects' level of anxiety.

Other methods established to examine social avoidance in humans include go/no-go and social incentive delay tasks, often operationalized by implementing social or monetary rewards and the avoidance of punishment [18-20]. HarariDahan and Bernstein [21] utilized the Key-Presses Task [22], which allows participants to shorten or extend the viewing time of a given stimulus, thereby enabling subsequent examination of avoidance behavior. In a synopsis of the animal to human translational paradigms relevant for approach-avoidance conflict decision making, Kirlic, Young, and Aupperle [23] highlight two classes of tasks that probe social approach-avoidance conflicts: (1) social trust games involving monetary incentives by which levels of trust and cooperation with other players are assessed and (2) eye gaze tasks, given that the attentive focus on other facial expressions is crucial for enabling social interactions. Less fixation 
on the eyes as well as gaze aversions are distinctive features of social avoidance and social anxiety disorders [2, 24-27].

\section{Neural mechanisms of social avoidance in humans}

Consistent with the premise that social avoidance is characterized by a fear-driven propensity to reduce feelings of anxiety and shame in social contexts [2], the amygdala has been identified as one of the core regions involved in social avoidance in humans. Several studies report an amygdala hyperactivation in response to socially threatening cues, e.g. fearful and angry faces [20, 28, 29]. Exaggerated amygdala reactivity is also associated with a greater preferred distance to such stimuli [30]. Amygdala reactivity varies according to subjects' level of anxiety, with highanxious and high-avoidant participants exhibiting greater amygdala responses, especially when facing social feedback or decisions of whether or not to engage in social interaction [17, 20,31]. Interestingly, similarly exaggerated amygdala activity towards socially threatening stimuli has been modeled after the injection of endotoxins, aimed at causing an inflammatory response in healthy subjects. The resultant feelings of disconnection have been interpreted as reflecting sickness-induced social withdrawal [32], which therefore is another potential source of avoidance behavior in humans. Increased amygdala activation has also been associated with delayed responses during a forced approach to fearful faces, confirming the involvement of the amygdala in orchestrating fear-induced social avoidance [18]. Normally the amygdala does not act in isolation but is tightly top-down controlled by the anterior prefrontal cortex (aPFC) [33]. Consistent with this model, Kaldewaij et al. [4] conclude that voluntary regulation of approach-avoidance behavior is marked by aPFC-induced top-down inhibition of the amygdala. With the advent of better tasks and high-resolution fMRI, specific roles have been attributed to subdivisions of the aPFC. First, the lateral frontal pole (FPI) has been implicated in regulating action tendencies subserving the control of approachavoidance behavior via the ventral amygdalofugal bundle [34]. Second, affect-incongruent responses during the AAT evoke increased activity in the left lateral orbitofrontal cortex (OFC), underlining the importance of this subregion in control of approach-avoidance behavior [6]. Socially anxious subjects not only display an increased amygdala response to negative social stimuli, but also decreased activity in the nucleus accumbens (NAc) while receiving positive feedback from a social partner [17], suggesting that the mesolimbic reward circuit is dysfunctional in social avoidance. Possibly related to this are increased striatal responses to angry vs. happy faces in go/no-go tasks, as has been documented in high-avoidant participants [20]. Furthermore, increased ventral striatum/
NAc activation was triggered by the anticipation of both avoiding social punishment or receiving a social gratification [19], suggesting that social avoidance can be highly rewarding and thereby stimulate a gain of illness.

Since the amygdala and NAc both possess important roles in the neural processing of social avoidance, functional connectivity between the two may be relevant. Indeed, during decisions whether or not to engage in social interactions, higher levels of anxiety were found to be associated with increased functional connectivity between the right NAc and the amygdala, accompanied by decreased functional connectivity between the right NAc and the perigenual anterior cingulate cortex (pACC) [17]. Chang and Yu additionally highlight the importance of the thalamo-hippocampal-insular/midbrain circuit, where resting-state effective connectivity changed in response to the TSST [35]. Overall, there is limited evidence regarding the underlying neural substrates of social avoidance in healthy humans. Most studies investigating the neural and behavioral underpinnings of social avoidance in healthy subjects have employed the AAT in various versions and in combination with the TSST. Of note, the AAT rather reflects automatic approach-avoidance tendencies than an actual decision process. Meanwhile, more recent approaches in the research of social avoidance have emerged, including go/no-go and other decision-making tasks. The majority of studies apply emotional facial expressions as experimental triggers of social avoidance responses, given that these stimuli represent salient carriers of nonverbal social information. Neuroimaging results emphasize the importance of amygdala, striatum/NAc, and their interactions, as key neural substrates of social avoidance, with topdown control of approach-avoidance actions being mediated by anterior prefrontal regions (summarized in Fig. 1). Thus, the neural underpinnings of social avoidance resemble those implicated in general avoidance behavior [36-38] and emotional processing (for a summary see [4]).

Overall, the evidence largely confirms the vigilanceavoidance hypothesis, which describes an enhanced vigilance towards social threat in socially anxious subjects, followed by avoidance behavior [39]. High-avoidant participants additionally display an impassiveness to social reward [40]. Furthermore, the response patterns measured in fMRI studies involving social reward and punishment $[17,19]$ often resemble those found with non-social incentives tasks [41, 42]. Such overlap has already been observed by Lin et al. [43]. Further research is needed to distinguish precisely between non-social and social avoidance to clarify ambiguous results. More recent advances in fMRI study design include a shift from static to dynamic approaches (e.g. virtual reality paradigms or video recordings), which might be beneficial for creating a more natural setting [44-46]. Despite technical hurdles, hyperscanning methods capturing two-person dyads are also becoming more relevant $[44,47]$. 


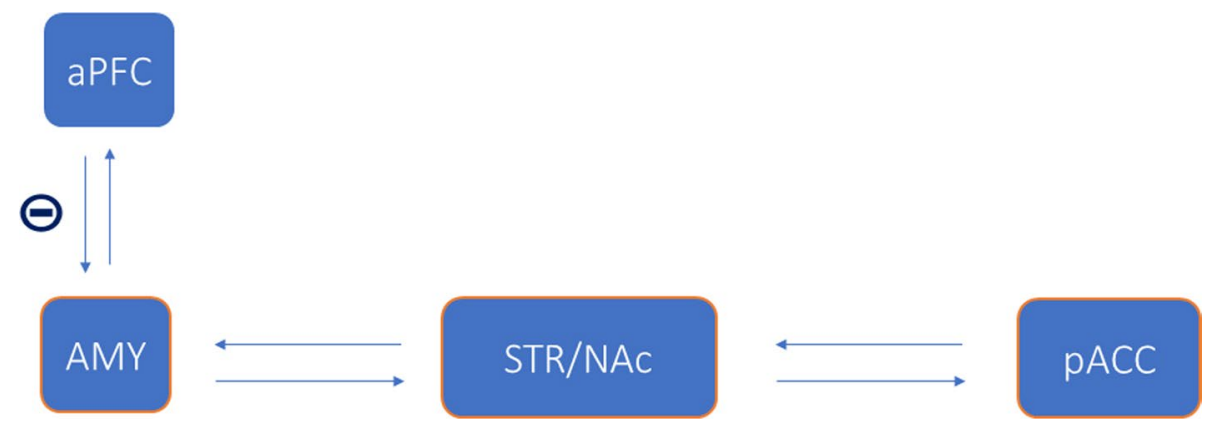

Fig.1 Neurocircuits associated with social avoidance in the healthy human model. Based on findings that: (1) The aPFC regulates approach-avoidance actions by top-down inhibition of the amygdala. (2) The amygdala has repeatedly been found to be hyperactive in response to social threat, specifically in socially anxious and avoidant participants. (3) The mesolimbic reward circuit is possibly altered

\section{Pathological social avoidance in humans}

If its intensity and/or frequency exceeds a certain level, social avoidance develops into pathological forms that can lead to complete social isolation, inability to work, and significant suffering. Social avoidance ranges on a stepless spectrum from functional-adaptive to inflexible-maladaptive. In principle, two forms of pathological social avoidance can be discriminated against, namely social anxiety with and without paranoid symptoms. The latter are mainly characterized by a biased perception of reality (attribution bias), that leads to irrational mistrust and suspicion of others and thus often also to hostile beliefs and rejection hypersensitivity [48].

\section{Social anxiety disorder (SAD)}

Pathological social avoidance can occur, at least transiently, in almost any psychiatric disorder except acute mania and is, furthermore, the main characteristic of a social anxiety disorder (SAD) which is also called social phobia, e.g. in the ICD-10 diagnosis catalog. Besides SAD, social anxiety occurs very frequently in patients with an avoidant personality disorder. SAD is one of the most frequent mental illnesses [49] with an approximate lifetime prevalence rate of $12.1 \%$ [50]. There are several rule-outs to consider before diagnosing the symptom of social avoidance or psychiatric disorder SAD. Importantly, introversion and shyness are sometimes misconstrued as SAD, but are certainly within the normal limits of personality characteristics. Diagnosis criteria for SAD vary slightly between the ICD-10, DSM-5 and the upcoming ICD-11 diagnosis catalogs which define mental disorders according to phenotypic characteristics. In ICD-10, criteria for social phobia are met if an individual suffers from significant emotional distress either due to the non-psychotic fear of being in the center of attention or due in socially anxious participants as indicated by reduced NAc activity in response to social reward. (4) The functional connectivity between the amygdala and NAc, as well as NAc and pACC, alters as a function of social anxiety. $a P F C$ anterior prefrontal cortex, $A M Y$ amygdala, STR striatum, $N A c$ nucleus accumbens, $p A C C$ perigenual anterior cingulate cortex

to the fearful avoidance of social situations, given that he or she concomitantly considers these symptoms, including the characteristic fear to embarrass oneself in social situations, as excessive and unreasonable. In addition, two anxiety symptoms according to criterion B of the ICD-10 diagnosis agoraphobia need to be present together with either blushing, urgency or fear of micturition/defecation and/or fear of vomiting during the feared social situation. Finally, this symptom complex should be restricted to the feared situation and should not occur due to other disorders such as schizophrenia to fulfil the ICD-10 criteria of social phobia [51]. In ICD-11, among other changes, the social phobia has been termed SAD like in DSM-5 and, furthermore, a specification that symptoms must endure for at least some months has been added to its diagnostic criteria [52]. In contrast to ICD10, DSM-5 illustratively summarizes general, psychological, and somatic anxiety symptoms occurring in SAD under the term "panic attack" and, furthermore, highlights differences in the clinical presentation of SAD between children and adults by stating that the duration of the SAD syndrome must persist at least 6 months in individuals under 18 years [53].

Criteria of psychiatric diagnoses such as SAD can be assessed in clinical expert interviews and by validated diagnosis-specific and/or transdiagnostic inventories. The widely used Structured Clinical Interview for DSM (SCID) has been proven to detect SAD with reasonably high specificity and sensitivity [49, 54]. Interestingly, some of the instruments assessing specifically the presence and intensity of social anxiety have been published long before the official recognition of SAD as a psychiatric illness in 1994 [55] e.g. the Social Avoidance and Distress Scale published in 1969 [56]. Today, the Liebowitz Social Anxiety Scale is one of the most used self-rating scales for social anxiety assessment [55]. In addition, there are a number of other valuable instruments for SAD assessment such as the Social Phobia 
Inventory, the Brief Social Phobia Scale and the Social Phobia and Anxiety Inventory [55].

\section{Other psychiatric conditions associated with social avoidance}

Psychiatric disorders are generally highly comorbid with each other. It is well accepted that SAD is more frequent in female than in male subjects $[57,58]$. Some researchers found sex differences in SAD comorbidity patterns. For instance, in the US National Comorbidity Survey-Replication sample, women with SAD were more likely to suffer from comorbid posttraumatic stress disorder (PTSD), specific phobia, generalized anxiety disorder (GAD), whereas men suffering from SAD were more likely to have conduct disorder and comorbid substance abuse [57]. However, these findings are not surprising as the latter two diseases are known to be principally more frequent in men and anxiety disorders and PTSD are generally more frequent in women. In a cohort from the German Mental Health Survey, 2\% suffered from full DSM-IV SAD, 3\% from symptomatic (i.e. one DSM-IV criterion missing) and 7.5\% from subthreshold SAD. $87.8 \%$ of the subjects with full SAD suffered of at least one other mental disorder during the past 12-month period with $60 \%$ of them having three or more comorbid disorders and only $12.2 \%$ showing no comorbid condition with pure cases being younger than comorbid cases [58]. In this sample, all three SAD groups were associated with obsessive-compulsive disorder (OCD) as well as with anxiety disorders, particularly with GAD, panic disorder (PD), and agoraphobia [58].

Social evaluative concerns are the most common type of paranoid thoughts [59]. Paranoid ideas are usually accompanied by aversive emotions ranging from mild feelings of discomfort to intense distress. Social avoidance due to paranoid thoughts occurs frequently inter alia in paranoid personality disorder and, together with passive social withdrawal, also in schizophrenia [60]. In schizophrenic patients, passive social withdrawal, which occurs due to lack of motivation, is related more to negative symptoms while social avoidance is related more to positive symptoms and is an active behavior resulting from unwarranted fear, hostility or distrust [61].

\section{Treatment of social avoidance in neuropsychiatric disorders}

Avoidance is a behavioral manifestation of fear and anxiety that tends to generalize particularly in individuals with an elevated vulnerability for mental disorders. PTSD patients avoid trauma-related cues, GAD patients avoid a constantly increasing amount of everyday risks, and phobic patients the object of phobia such as social situations in the case of SAD. Accordingly, cognitive-behavioral treatments (CBT) targeting pathological avoidance by gradual exposure to stimulating cues are effectively used in the treatment of SAD and other anxiety disorders [62, 63]. Patients suffering from these conditions also significantly profit from pharmacotherapy, in particular from treatment with serotonin reuptake inhibitor antidepressants such as paroxetine which has repeatedly been shown to act effectively against SAD in adult patients [64, 65]. Accordingly, paroxetine, sertraline, and the serotonin-noradrenaline reuptake inhibitor venlafaxine have been approved by the FDA for SAD treatment [66]. Furthermore, some experimental treatment approaches such as augmentation of exposure-based CBT with the partial NMDA receptor antagonist D-cycloserine [67] constitute promising potential novel treatment options for social anxiety. Schizophrenia-associated social avoidance was shown to improve significantly in response to treatment with antipsychotics [68, 69]. In summary, these facts point at divergencies in the neurobiological underpinnings of pathological social avoidance with and without paranoid and psychotic symptoms and stimulate the hypothesis that the latter might be associated rather with an impaired serotonergic transmission while social avoidance with paranoid and psychotic symptoms might possibly be related to excessive dopamine signaling.

\section{Neural mechanisms of pathological social avoidance}

The high comorbidity of psychiatric disorders points at the imprecision of their definitions that calls for a novel biology-informed taxonomy. Accordingly, meta-analyses have shown that genetic alterations as well as changes in brain structure and function in psychiatry are often non-specific with similar or even identical changes appearing in distinct mental disorders [70]— the same accounts for neural, endocrine and molecular mechanisms in SAD patients. A very recent review aimed at untangling the functional network alterations of anxiety disorders and revealed that SAD patients show alterations in the functional connectivity (FC) of several frontal regions (i.e. the orbital cortex, the prefrontal cortex (PFC) and the ACC) with the limbic system (i.e. the hippocampus, the amygdala and the temporal lobe) while GAD patients are characterized by limbic-prefrontal and mesocorticolimbic FC changes and PD patients show limbic-PFC and frontoparietal FC alterations in emotional and network tasks, respectively, as well as ACC-amygdala FC changes [71]. A meta-analysis of functional neuroimaging studies performed during treatment of SAD concluded that psychotherapy and pharmacotherapy impact on different brain regions in adult SAD patients with the amygdala being influenced by neither treatment [72]. In contrast, a more recent review on neuroimaging amygdala response markers for SAD treatment found that responses of the amygdala decreased, and the FC of amygdala pathways changed in 
response to treatment of SAD [73]. In accordance, a justpublished fMRI-study suggested a better long-term outcome of treatment to be associated with strengthened amygdala connectivity with regulatory regions while poorer treatment effects were paralleled by changes in sensorimotor and visual areas [74]. Several recent volumetric MRI studies suggested a role for the striatum, a critical component of reward and motor systems, and related constructs (e.g. intolerance of uncertainty) in SAD [70]. In detail, SAD has been found associated with an enlarged striatal volume [70] that, in turn, could be reduced, at least in two striatal subregions, by successful paroxetine treatment $[70,75]$. However, findings on the striatal volume in SAD are not unequivocal [76] thus pointing to the necessity for additional studies with larger sample sizes [70] as well as to the importance of confounders which comprise comorbid disorders, age, and drug treatment [76]. In the latter meta-analysis that includes eleven studies on the grey matter volumes (GMVs) of different brain regions of SAD patients vs. healthy controls (HC), the GMV of the left putamen, which is a part of the dorsal striatum, was reduced in SAD while those of the supplementary motor area (involved in motor control), the middle occipital gyrus (involved inter alia in object recognition) and the left precuneus (involved inter alia in episodic memory, visuospatial processing, and reflections upon self) were found to be enlarged [76]. Another meta-analysis showed that the neural response within the face-processing system in SAD involves a complex network and is not limited to emotional structures as faces evoked a higher response in SAD not only in limbic regions such as in the bilateral amygdala but also in non-limbic structures such as the globus pallidus (implicated in motor control), the visual cortex, the superior temporal sulcus (implicated in social perception) and the PFC (involved in executive functions such as decision making) [77]. Despite the inconsistencies of the studies on the role of brain regions and networks in $\mathrm{SAD}$, there is considerable evidence for a (non-exclusive) role of the limbic system, the sensorimotor and visual areas, and their networks in SAD pathobiology.

\section{Modulators of social avoidance in humans}

\section{Glucocorticoids}

Cortisol is the major effector hormone of the hypothalamic-pituitary-adrenal (HPA) axis, which, together with the sympathetic nervous system (SNS) forms the two main stress hormone systems in humans. Since both systems are essential for stress coping, they belong to the most studied biological systems in clinical psychiatry. Studies indicate augmented processing of social threat after cortisol administration, which may be specific to high-avoidant and high-anxious participants [78, 79]. Furthermore, high cortisol levels in response to the TSST are correlated with heightened avoidance of social threat in SAD patients [10] as well as diminished active approach-avoidance behavior [5]. The latest meta-analysis of cortisol reactivity in response to psychosocial stress in mental disorders revealed significant differences between male and female SAD patients as men, but not women exhibited an increased cortisol response to psychosocial stress. In addition, the authors found sex-dependent differences in HPA axis reactivity also among other mental disorders such as major depression and schizophrenia [80]. A study on the influence of psychosocial stress on the HPA axis reactivity in females suffering from PTSD identified two HPA axis reactivity subgroups with an almost identical expression of PTSD symptom severity but a difference in the intensity of trauma-related dissociative symptoms and of the prevalence of combined early life and adult traumatization [81]. The latter suggests that these endocrine differences might possibly result from well-known trauma-induced epigenetic shaping of HPA-axis related genes [82] which might occur in any (psychiatric) disorder and, thus, would be an interesting topic to study in SAD patients. In comparison to major depression, $\mathrm{PD}$, and PTSD, the epigenetic regulation of the HPA axis seems to be markedly understudied in SAD.

\section{Testosterone}

Social approach-avoidance actions are influenced by different modulators of mood and behavior. For instance, single-dose administration of testosterone promotes an increased approach to social threat, accompanied by decreased social avoidance, in healthy controls [83, 84] as well as in SAD patients [24, 85]. Accordingly, SADassociated social avoidance behavior has been linked to low endogenous testosterone levels [86], indicating a dysregulation of the hypothalamic-pituitary-gonadal (HPG) axis with possible effects on SAD-relevant brain networks [87]. Furthermore, a recent clinical study showed that endogenous testosterone levels in females are predictive of the success of exposure therapy in SAD patients with low baseline and high reactive pre-treatment testosterone levels being related to larger post-treatment reductions in symptom severity [86]. The testosterone-induced bias away from avoidance towards the approach of social threat may result from the influence of testosterone on the amygdala, prefrontal cortex, and their interactions [88-90]. At the social-behavioral level, these findings are likely reflected by the established role of testosterone in enhancing social dominance to defend social rank [89] - an effect which is regulated by cortisol [91]. 


\section{Oxytocin}

A neuropeptide hormone, whose anxiolytic $[92,93]$ and prosocial effects in humans $[94,95]$ are well established, is oxytocin (OXT). Oxytocin has been associated with a variety of mental disorders such as major depression, schizophrenia, anxiety disorders [96], PTSD [97], and also with SAD $[98,99]$ and was, furthermore, found to be associated with emotional neglect in children [100]. Endogenous peripheral oxytocin levels have been found reduced in SAD patients during a trust game [101]. A genetic study associated genetic variants of the oxytocin gene with adolescent social anxiety symptoms and an epigenetic study revealed that, in SAD patients, reduced methylation of the oxytocin receptor (OXT-R) gene was related to increased symptom severity and to an elevated HPA axis response to social stress [99]. Nasal administration of oxytocin has been found to increase the social approach and decrease avoidance [21, 102-104], most likely by its inhibition of the amygdala [93, $105,106]$. It further counteracted SAD-associated alterations in the functional connectivity of various brain regions [96, 107, 108]. Table 1 summarizes studies on oxytocin treatment, among them one treatment study which revealed that oxytocin treatment did not reduce SAD symptom severity, although it at least resulted in several other beneficial therapeutic effects [109] and two fMRI studies found oxytocin to increase the connectivity of the amygdala with various other regions [107]. Two other studies showed an influence of oxytocin treatment on reward behavior $[98,110]$. Finally, another research group found that oxytocin application reduced the activities of both the amygdala and the PFC [106, 111].

While oxytocin-induced approach behavior in female subjects, at least in positive social contexts [112], pair-bonded male volunteers avoided attractive women, an effect which was absent in single men and may facilitate long-term relationships [113]. Given that the effects of oxytocin on social approach and avoidance are a person-and context-dependent, rigorous study designs are required to account for this complexity in future research.

\section{Dopamine and serotonin}

Oxytocin and testosterone both interact with the monoaminergic neurotransmitter systems including the dopaminergic pathways [114], which may be dysfunctional in social avoidance as indicated by the aforementioned alterations in the mesolimbic circuit. Indeed, SAD patients display both reduced density of dopamine uptake sites [115] and lowerthan-normal D2-receptor binding potential in the striatum [116]. Concentrating on extrastriatal brain regions, SAD symptom reduction correlates with increased D2 receptor binding in medial prefrontal and hippocampal regions [117], however, overall prefrontal D2 receptor levels were found to be elevated [118]. Although the evidence is limited and inconsistent, SAD may be characterized by altered dopaminergic neurotransmission. Together with dopamine, the serotonergic (5-HT) system is one of the key neurotransmitter pathways underlying social-emotional processing. An increase in serotonin levels mediated by selective serotonin reuptake inhibitors (SSRIs) or supplementation of the precursor tryptophan, is associated with positively biased processing of social stimuli [119-121]. Conversely, decreased serotonin levels after tryptophan depletion have been revealed to cause a shift towards the increased perception of negative social stimuli, perhaps mediated by increased amygdala-prefrontal connectivity [122]. Tryptophan depletion further increases the autonomic stress response to social evaluation in SAD patients treated with SSRIs [123]. In addition, SAD patients display reduced serotonin-1A receptor (5-HT1A) binding in limbic and paralimbic regions, most significantly in the amygdala, anterior cingulate cortex, insula, and dorsal raphe nuclei [124]. There has been growing interest in genetic research to identify variations in the serotonergic system underlying altered social-emotional processing, with mounting evidence indicating the importance of a polymorphism in the promoter region (5-HTTLPR) of the human serotonin transporter gene (SLC6A4). Subjects carrying the 5-HTTLPR short allele display increased levels of anxiety and an increased amygdala response to social threat $[125,126]$ together with higher levels of social avoidance [127], compared to subjects with copies of the long allele. In contrast, Stein et al. [128] failed to demonstrate a genetic linkage between generalized social phobia and the serotonin transporter (5-HTT) or 5HT2A receptor genes. A recent positron emission tomography (PET)-study highlighted the importance of both, dopamine and serotonin, in SAD by reporting an association of SAD with an increased expression of dopamine and serotonin transporters in reward- and fear-associated brain regions [129].

\section{Brain-derived neurotrophic factor (BDNF)}

Excessive stress-induced signaling of glucocorticoid hormones such as cortisol inhibits BDNF synthesis and thereby reduces neural plasticity. The upregulation of BDNF through pharmacotherapy may reverse brain atrophy and thereby contribute to the antidepressant effect in stress-related disorders [130]. The BDNF single nucleotide polymorphism (SNP) Val66Met has been linked to increased attention towards the social threat, together with elevated amygdalaprefrontal connectivity as well as exaggerated amygdala and hippocampal responses to social cues in anxious and depressed patients [131, 132]. However, relative to animal models discussed in the second part of this review, data on the human BDNF polymorphism Val66Met and its relevance 


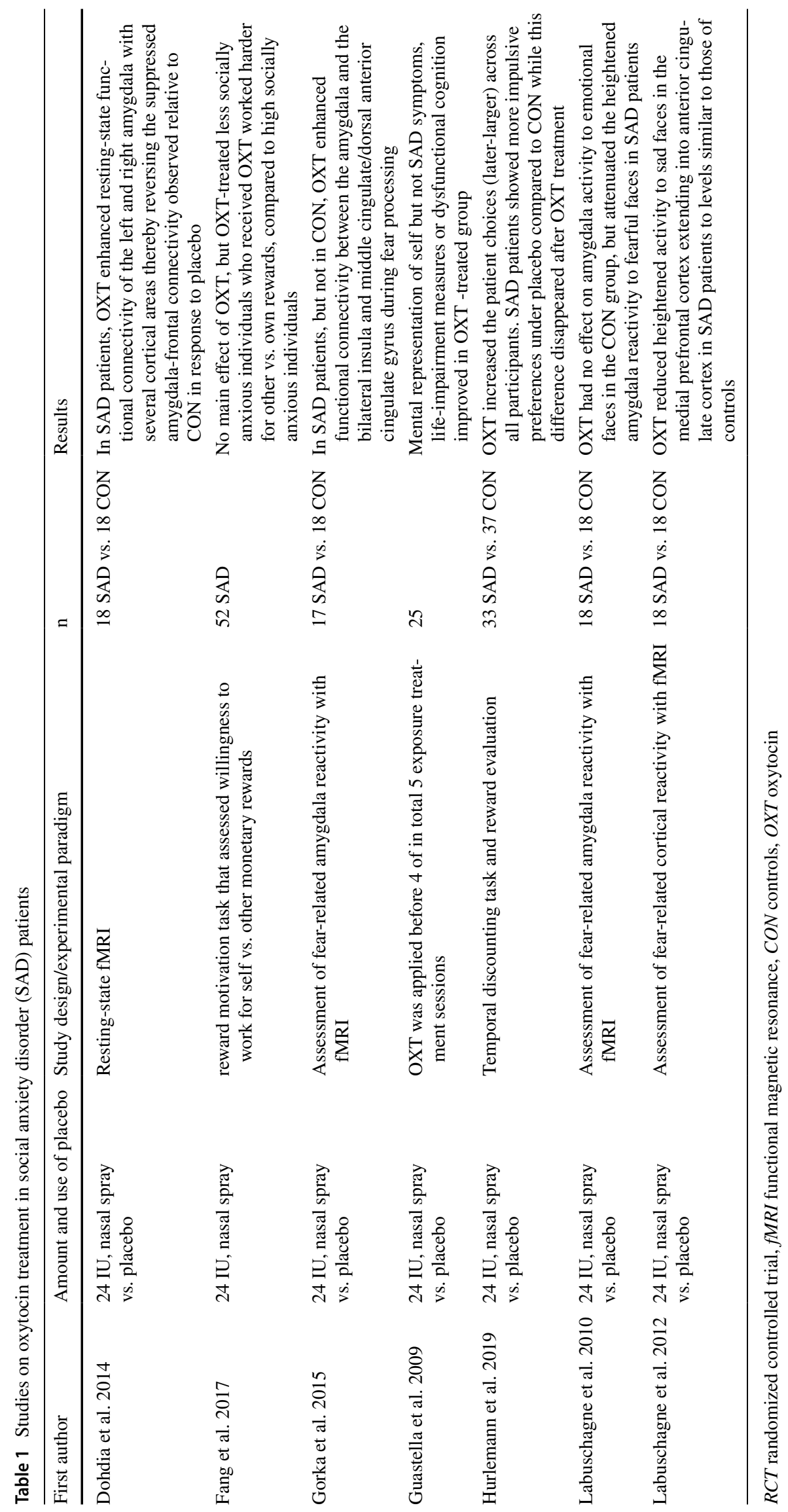


for social stress and avoidance is harder to interpret (see for review [133]). Different studies indicate both higher social anxiety scores in Met-carriers of both sexes [134], whereas males also showed attenuated perception of social stress and consecutive HPA axis response compared to male homozygous Val carriers [135], an effect found to be opposite in females [136]. Overall, human research on BDNF and social avoidance has received less attention despite being a valuable translational target for understanding neuroplasticityrelated effects.

\section{Endocannabinoids}

The endocannabinoid system (ECS) is a widely expressed neuromodulatory system involved in the regulation of various physiological and pathological processes. It is comprised of cannabinoid receptors $\mathrm{CB} 1$ and CB2, their endogenous ligands (endocannabinoids), and enzymes involved in endocannabinoid metabolism [137]. In the CNS, endocannabinoid signaling acts as a retrograde feedback mechanism at both excitatory and inhibitory synapses. Strong depolarization of postsynaptic neurons induces synthesis of the endocannabinoid 2-Arachidonoylglycerol (2-AG) that activates presynaptic CB1 receptors, which in turn inhibits further neurotransmitter release [138]. The ECS thus provides important homeostatic control over the neuronal activity. Components of the ECS are expressed in other CNS cells as well, such as astrocytes and microglia, thus enabling communication between cell types. Furthermore, the ECS has well-documented functions in peripheral tissues, including the regulation of immunological and metabolic processes $[139,140]$. Importantly, CB1 receptors are highly expressed in brain regions associated with the regulation of emotion, cognition, and stress-responses [141] and disturbances in endocannabinoid signaling have been implicated in a range of psychiatric disorders in both clinical and preclinical studies including social anxiety [142]. Strong evidence for the ECS' involvement in mental health came from observations on the anorectic drug rimonabant (SR141716), a selective cannabinoid receptor type 1 (CB1) inverse agonist [143], which caused serious mood alterations and depressive symptoms in up to $10 \%$ of patients, leading to a worldwide withdrawal of its approval in 2008 [144, 145]. Furthermore, there is some evidence linking genetic variation in the ECS to phenotypes related to social and emotional processing. In healthy subjects, SNPs in the CNR1 gene have been associated with differences in gaze duration and brain responses towards happy faces presented during fMRI studies [146, 147]. CB1 signaling might thus play a role in the perception of certain emotional/social signals. Furthermore, variants in ECS genes have been associated with several relevant personality traits or psychiatric disorders, including high neuroticism and low agreeableness [148], bipolar disorder
[149], and panic disorder [150]. In recent years, there has been a lot of interest in the therapeutic potential of cannabinoid substances, especially the phytocannabinoid cannabidiol (CBD) (reviewed by [151]). A few small clinical studies have demonstrated anxiolytic effects of CBD in patients with SAD or avoidant personality disorder, using anxiety questionnaires and/or simulated public speaking tests [152-154]. Functionally, the anxiolytic action of CBD was related to altered activity in limbic and paralimbic brain areas, assessed by regional cerebral blood flow [153].

In sum, it is the complex interplay of various modulators that influences social avoidance and guides behavior. Further research, especially in clinical populations, is mandatory. An overview of the aforementioned modulators and their influence on social approach-avoidance behavior is shown in Table 2.

\section{Investigation of social avoidance in animals}

Defining normal social behavior in animals, including its affiliative and aversive poles, depends on multiple factors like species, sex, age, and the environment they live in (i.e., laboratory vs. wildlife). Social behavior comprises and requires approach and avoidance, interaction, recognition, and formation of memories and can be driven by social reward or fear. In rodents and other gregarious species, fear of new social interaction partners is usually overcome by the physiological drive to socially approach and interact. These opposing processes are regulated via different brain circuitries and neurotransmitters and -modulators $[155,156]$. We want to reflect on the structural and molecular mechanisms of social avoidance and withdrawal in the context of animal models and stressors, which are linked to the aforementioned human behavior and neuropsychiatric disorders.

Social avoidance in animals is evoked by social adversity or threats, such as social isolation or instability, maternal separation or abuse, social fear conditioning, subordination, and social defeat [157]. Systemic injection of lipopolysaccharides (LPS), bacterial endotoxins eliciting a strong inflammatory response, transiently (up to $12 \mathrm{~h}$ ) also induces social withdrawal as part of sickness behavior [158] and can be attenuated by anti-inflammatory drugs like minocycline that reduce cytokine expression in the hippocampus [159]. Nevertheless, social stressors are far more common in research on social avoidance and fear. Especially social defeat models, based on the resident-intruder paradigm, offer acute (1 day) or chronic (up to $30 \mathrm{~d}$ ) time frames to elicit different sets and durations of symptoms [160,161] and bear high translational value [162]. Assessment of avoidance comprises variations of confronting the test animal with a shielded or freely accessible familiar or unfamiliar, sameor opposite-sex, younger or dominant counterpart and the choice to interact or not $[157,163]$. Interpretation of the 
Table 2 Modulators of social avoidance in humans

\begin{tabular}{|c|c|}
\hline Modulator & Findings \\
\hline Testosterone & $\begin{array}{l}\text { Increase } \\
\text { Promotes social approach and decreases avoidance of social threat } \\
\text { Decrease } \\
\text { Low endogenous testosterone levels are linked to social avoidance in SAD } \\
\text { Other } \\
\text { Endogenous testosterone levels are predictive for therapy success in female SAD patients }\end{array}$ \\
\hline Cortisol & $\begin{array}{l}\text { Increase } \\
\text { Enhances processing of social threat, specific for anxious/avoidant participants } \\
\text { Correlates with increased social avoidance of social threat in SAD patients } \\
\text { Correlates with diminished active approach-avoidance behavior } \\
\text { Cortisol responses to psychosocial stress are elevated in male SAD patients }\end{array}$ \\
\hline BDNF & $\begin{array}{l}\text { Polymorphism linked to } \\
\text { Increased attention towards social threat } \\
\text { Exaggerated amygdala and hippocampal responses to social cues in psychiatric patients } \\
\text { Higher social anxiety scores } \\
\text { Increased cortisol responses to social stress in females but attenuated responses in males }\end{array}$ \\
\hline Oxytocin & $\begin{array}{l}\text { Increase } \\
\text { Increases social approach and decreases avoidance in a highly context-dependent manner } \\
\text { Counteracts SAD-associated alterations in the functional connectivity of various brain regions } \\
\text { Does not reduce SAD symptom severity but results in other beneficial therapeutic effects } \\
\text { Decrease } \\
\text { Endogenous peripheral oxytocin levels are reduced in SAD patients during a trust game } \\
\text { Other } \\
\text { Reduced oxytocin receptor methylation is related to: } \\
\text { an increased SAD symptom severity } \\
\text { an elevated HPA axis response to social stress }\end{array}$ \\
\hline Dopamine & $\begin{array}{l}\text { Extrastriatal D2 receptor levels are elevated in SAD patients } \\
\text { Increased D2 receptor binding in prefrontal and hippocampal regions correlates with SAD symptom reduction } \\
\text { Reduced striatal density of dopamine uptake sites and lower D2 receptor binding potential in SAD patients } \\
\text { Increased expression of dopamine transporters in reward- and fear-associated brain regions in SAD patients }\end{array}$ \\
\hline $5-\mathrm{HT}$ & $\begin{array}{l}\text { Increase } \\
\text { Induces a positively biased processing of social stimuli } \\
\text { Decrease } \\
\text { Increases perception of negative social stimuli } \\
\text { Increases stress response to social evaluation in SAD } \\
\text { Other } \\
\text { Reduced 5-HT receptor binding in limbic and paralimbic regions in SAD patients } \\
\text { Increased expression of serotonin transporters in reward- and fear-associated brain regions in SAD patients } \\
\text { Polymorphism of the 5-HT transporter gene linked to: } \\
\text { Increased levels of anxiety and social avoidance } \\
\text { Increased amygdala response to social threat }\end{array}$ \\
\hline
\end{tabular}

different tests depends on the preceding behavioral model or treatment, sex, age, and species under investigation and have to be chosen carefully as altered social interaction can occur independently or in combination with other symptoms linked to a depressive or non-socially anxious phenotype $[157,160,164]$.

\section{Neuronal networks underlying social avoidance in animals}

The circuitry determining social behavior involves the anterior and ventromedial hypothalamus, amygdala (AMY), the bed nucleus of the stria terminalis (BNST), lateral septum, periaqueductal gray (PAG) among others. It connects with the dopaminergic mesocorticolimbic motivation and reward network (ventral tegmental area (VTA), nucleus accumbens (NAc), and prefrontal cortex (PFC)) [155, 165].

The VTA serves as a dopaminergic hub modulating activity in the NAc and the medial prefrontal cortex (mPFC) and neuronal activity patterns in the VTA correlate with social interaction and avoidance [166-168]. Neuronal hyperactivity induced by a hyperpolarization-activated cation channel-mediated current $\left(I_{h}\right)$ was detected in the VTA of avoidant mice after social defeat stress $[169,170]$ and acute upregulation of $I_{h}$ currents by a single infusion of the antiepileptic drug and mood stabilizer lamotrigine similarly enhanced social avoidance [171]. Conversely, upregulation of voltage-gated potassium channels (VGKCs) 
Kcnf1, Kcnh3, Kcnq3 is triggered by even higher $I_{h}$ currents observed in non-avoidant mice and resulted in neuronal hypoexcitability in the VTA. Inline, local induction of hypoexcitability in the VTA by either genetic upregulating of potassium channels [169] or pharmacological potentiation of $I_{h}$ current via infusion of lamotrigine for 5 days [171] restored normal social behavior. Neuronal properties within mesocorticolimbic projections were found to be discriminatory of avoidant vs. non-avoidant phenotypes after social defeat stress with an activity increase in mesolimbic VTA-NAc projections whereas decreased firing rates were observed in the VTA-mPFC connection [167, 172, 173]. The relevance of these distinct pathways in the context of stressinduced social avoidance was demonstrated when phasic, not tonic, optogenetic stimulation was capable to elicit social avoidance in live animals by either activation of the VTANAc $[167,172,173]$ or inhibition of the VTA-mPFC projections [167]. Moreover, inhibition of the VTA-NAc connection turned avoidant into non-avoidant phenotypes [167]. Together, these findings underline how circuit-specific alterations of excitability underly social interaction and its disruption. Mechanistically, chronic but not acute treatment with the antidepressants fluoxetine and imipramine restored normal social behavior in avoidant mice, which-for fluoxetine-was accompanied by normalized excitatory properties of VTA neurons as well as the reversal of gene expression changes in the NAc [170, 174]. Together, these findings demonstrate the importance of balanced neuronal activity in the VTA in social behavior. Golden et al. demonstrated, that besides altered functional plasticity described before, also structural plasticity is disrupted in brain regions modulating social behavior: they discovered a reduction of the small Rho GTPase Rac1, which is involved in synaptic remodeling, in the NAc of avoidant mice. Normal social behavior was in turn restored together with neuronal structural plasticity by constitutively inducing Rac1 activity [175].

Within the circuitry of VTA, NAc and mPFC, activation of projections from the infralimbic part of the PFC to the NAc reversed social avoidance in mice [176]. In line with this, the activation state of the mPFC is relevant for the formation of social avoidance after psychosocial stress. After exposure to chronic social defeat stress (CSDS), reduced expression of the immediate-early genes Zif268 and Arc indicated decreased neuronal activity in the mPFC specifically in those mice that developed social avoidance [177] and this avoidant phenotype could be abolished by optogenetic stimulation of neuronal activity the mPFC during social interaction [177]. Similarly, the downregulation of Zif268 expression in the mPFC was shown to induce social anxiety [178]. Inline, upregulation of delta-FosB, a transcription factor enhancing inhibitory neurotransmission mediated by cholecystokinin (CCK) between interneurons and pyramidal cells [179], in the mPFC was only found in socially avoidant animals [176]. Stress duration impacts not only the set of symptoms but also gene expression patterns in the PFC. In a study by Bondar et al., 10d of CSDS sufficed to induce social avoidance in mice when confronted with an aggressor in the absence of other behavioral changes associated with depression. This was accompanied by a high level of gene regulation in the PFC and upregulation of pathways related to the formation of extracellular matrix and cell adhesion that can eventually alter cortical neuroplasticity. After $30 \mathrm{~d}$ of continuous defeat stress, a more severe phenotype emerged with generalized social avoidance and symptoms of depression whereas most of the initially regulated genes of the 10d group had returned to control levels. These adaptions could be linked to epigenetic mechanisms as chromatin remodeling histone methyltransferases were significantly enriched and downregulated in the depressive $30 \mathrm{~d}$ group vs. the $10 \mathrm{~d}$ stress group. In contrast, a distinctively different, smaller set of genes, mostly related to neuroplasticity like spine dynamics and neurotransmission, was found to be downregulated in the PFC of depressive, generally socially avoidant mice [180]. This points us towards highly adaptive processes during prolonged periods of stress that include reversal of early effects already concomitant with signs of social dysfunction. Eventually, this mounted in a complex avoidant phenotype associated with dynamic, plastic neuronal networks. Slower neuronal conduction in the PFC might also be a relevant mechanism for developing social avoidance. Hypomyelination and myelin remodeling occurred in socially avoidant mice after CSDS or chronic social isolation [181, 182]. Induction of demyelination in the mPFC led to social withdrawal and both spontaneous remyelination [182] and pharmacological enhancement of myelination [181] normalized social behavior. The authors hypothesized a defect of the differentiation of oligodendrocyte progenitor cells induced by chronic social defeat stress [182]. In line with this, mice deficient for the myelin paranode protein CNP1 show social withdrawal at baseline [183] and are more susceptible to stress-induced avoidance [184].

The PFC is directly connected to other brain regions controlling anxiety and fear responses and dysfunction of these networks reflect a pathophysiological mechanism underlying social avoidance. Disrupted feedback control between PFC, AMY and VTA is suggested as an important cause for CSDS-induced avoidance in mice $[185,186]$. In hamsters, avoidant behavior after the conditioned social defeat was associated with a lack of activation in projections from the mPFC to the amygdala [187]. The mPFC also normally exerts top-down control over parts of the brainstem (periaqueductal gray, PAG) to modulate social approach and avoidance and disruption of this connection was found to induce social avoidance [188]. Activation of the PAG together with context-specific circuits of the ventromedial hypothalamus was also detected in the face of social threats $[189,190]$. 
Volumetric magnetic resonance imaging (MRI) studies in rodents also tried to detect specific anatomic alterations in avoidant phenotypes. In a post hoc analysis, the size of the hypothalamus was increased, while that of the bed nucleus of stria terminals (BNST), component of the extended amygdala [191], and dorsal raphe nuclei (DRN) in the brainstem was decreased [192]. While the BNST has recently been reviewed extensively as a mediator of social salience in aversive social contexts via oxytocin [193], the DRN serves as the major brain-wide source of serotonin (5HT) but also specifically promotes activation of the VTA-NAc pathway via serotonin and glutamate signaling [194]. There is a general influence of social stimuli on hippocampal function and neurogenesis proven in adult mammals [195] although the role of aversive stimuli is less clear. Hippocampal alterations found with avoidance behavior also depend on the age in which it is provoked. In juvenile mice, social stress-induced avoidance correlated with chronically suppressed hippocampal neurogenesis [196] that is required for forming normal social behavior [197]. In adult rodents, persistent avoidant behavior correlated with chronically increased hippocampal neurogenesis, possibly as a compensatory mechanism after initially suppressed neurogenesis [198]. Data on volumetric changes in adult avoidant animals after chronic psychosocial stress is not consistent, showing either arrested growth [199] or increased volumina [192] of hippocampi. Interestingly, a pre/post MRI study revealed higher hippocampal volume as a predisposition for developing social withdrawal after chronic social stress [199]. The ventral hippocampus (vHPC) serves as information storage for memorizing and evaluating social stimuli [200]. It sends glutamatergic inputs to the NAc that specifically determine susceptibility for social avoidance, as enhancement of this transmission clearly promoted avoidant behavior [201]. The amygdala and its subdivisions are widely connected [202] with other brain regions relevant for social behavior, including the circuitries formed with the mPFC [176] described above, but also with the hippocampus. These connections modulate social behavior and fear, as activation of the basolateral amygdala (BLA) in primates [203] and specifically of the BLA-vHC circuitry in rodents [204] reduced social interaction in a variety of social settings.

Neuronal networks adapt at different time scales to changing tasks by modulating synaptic connections, often referred to as synaptic plasticity. It describes the ability of existing synapses to strengthen or weaken over time and functionally, these plastic changes are mediated by altering the number of neurotransmitter receptors at the post-synaptic site or the pre-synaptic release of neurotransmitters. The hippocampus is probably the best-studied brain region in synaptic plasticity, but its adaptions regarding social avoidance are less clear. Recently, it was demonstrated that CSDS animals with a socially avoidant phenotype show no hippocampal long-term potentiation (LTP) [205]. Unfortunately, this study did not additionally compare the non-avoidant phenotype emerging from chronic stressor. Yet, another study showed no difference in LTP after CSDS, but an increased long-term depression (LTD) mediated by the metabotropic glutamate receptor mGluR5 [206]. These two recent studies confirm the heterogenous picture; however, induced behavior of social avoidance in special or stress in more general clearly manifests in changes of synaptic function. The apparently contradictory findings in functional synaptic plasticity might reflect the complexity of the system. Especially the underlying electrophysiological methods rely on several parameters that can change the outcome. While LTP and LTD is classically studied in young adolescent animals ( 3 to 6 weeks of age), the induction of social avoidance is mostly based on older animals.

\section{Modulators of social avoidance in animals}

\section{HPA axis and glucocorticoids}

Under healthy conditions, a well-concerted oscillation of circulating glucocorticoid hormones is maintained by the HPA axis in both animals and humans. The hypothalamus stimulates the pituitary gland with corticotropin-releasing hormone/factor (CRH, CRF), thereby sending adrenocorticotropic hormone (ACTH) to the peripheral adrenal cortex, which in turn secretes cortisol in humans and corticosterone (CORT) in rodents into the bloodstream. These glucocorticoids exert their effects via the glucocorticoid receptor (GR), which is widely distributed in the brain and most other peripheral tissues [207, 208]. The HPA axis contains several feedback loops both within the brain and in the periphery. Within the brain, binding of glucocorticoids to the GR in the hippocampus or hypothalamus inhibits CRH synthesis, which eventually lowers circulating glucocorticoid levels. The HPA axis is a physiological system helping the organism to cope with physical and psychological stressors, influences social interaction [209], matures with aging and its dysregulation has been extensively studied in the face of neuropsychiatric disorders and in their preclinical models [210, 211].

Dysregulation of the HPA axis is not only found in impaired adult social responses but also at juvenile life stages in animals as well as in socially anxious children and adolescents [212]. Several stress models in animals effectively induce social avoidance in pre-adult age stages, in part with delayed onset of avoidant behavior [213] and often temporally dissociated from other affective symptoms found in adult rodents [196, 214, 215]. One marker of social avoidance in those juveniles is reduced HPA reactivity in response to social interaction [213, 215]. Interestingly, social 
withdrawal in juveniles that had been exposed to an abusive mother could be rescued via systemic application of corticosterone [216], whereas exogenous corticosterone in adults induced avoidance in previously unaffected animals after chronic social defeat [217]. Hence, HPA response to social interaction depends on age and context but ultimately influences social behavior.

Circulating corticosterone levels have been studied repeatedly in various social stress models but mostly in chronic social defeat variations that induce social avoidance. In general, the elevation of blood corticosterone is found both in socially avoidant and non-avoidant mice directly after classic CSDS and thus is unlikely the direct cause of the disrupted social interaction [169] but rather the complex downstream- and feedback mechanisms within GR-signaling. Social avoidance after CSDS is not only accompanied by elevated plasma CORT but also higher expression of CRH in the hypothalamus, demonstrated to rely on gene demethylation and decreased GR expression in the hypothalamus and in the hippocampus of avoidant animals $[218,219]$. Systemic treatment with the antidepressant imipramine attenuated both avoidant behaviors together with Crf mRNA methylation levels indicating drug effects on the epigenetic level [219]. Systemic direct inhibition of the GR during CSDS prevented social avoidance in adult mice [196]. Antidepressants are thought to exert part of their effects via modulation of the GR [211]. Treatment of avoidant mice with the selective serotonin uptake inhibitor (SSRI) escitalopram restored social interaction, lowered plasma corticosterone, and restored GR protein expression in the hippocampus [218]. The flavonoid icariin, investigated for its antidepressant efficiency alleviated social avoidance and lowered hypothalamic CRH mRNA potentially via restoration of decreased GR levels in the hippocampus [220]. In the $\mathrm{mPFC}$, regulation of mainly glucocorticoid-responsive genes was found in avoidant animals after 10 but not 30 days social stress, indicating a high relevance of GC-dependent mechanisms for the initiation of social avoidance but not primarily for its sustainment [180]. Alteration of HPA function appears to be at least in part independent of the specific social stressor applied to the individual: Socially deprived mice developed signs of social avoidance and HPA hyperreactivity (elevated plasma CORT and adrenal gland weight) [221] and undefeated rats housed with defeated cagemates also developed avoidance together with a hyperactive HPA axis [222], revealing the contagious quality of social stress and reinforcing translational value of animal models.

\section{Testosterone}

Most animal research regarding social behavior is traditionally performed in males, neglecting the relevance of sex differences [223]. In most gregarious species used in the laboratory environment (mice, rats), adult males are more dominant, territorial, and easily demonstrate aggressive same-sex behavior in contrast to their female conspecifics which is mainly attributed to the dimorphism for the gonadal steroid hormone testosterone [224].

Data on testosterone in avoidance behavior of males is not clear-cut: Lowered testosterone levels were repeatedly found in submissive, fight-avoidant males ranging from rats [225] and hamsters [226] to rhesus monkeys [227] although others found them unchanged in subordinate hamsters [228] or rats [229]. In general, sex differences have been addressed in too few studies regarding social avoidance so far with a distinct exception for the "social hormone" oxytocin (see later section). Stack et al. found molecular changes in the frontal cortex of males but not females modulating social interaction and the authors hypothesized testosterone to normally prevent downregulation of neuronal activity in this brain region underlying social avoidance [178]. It was only recently shown in a non-social stress model how resilience in males was mediated by testosterone by lowering vHPCNAc excitability [64]. As the same projection was found to regulate resiliency towards social stress [201], its sexhormone dependent exploration has interesting implications for humans and should be considered in future studies.

\section{Oxytocin}

Oxytocin (OXT) is a highly conserved neuropeptide found in humans and animals modulating social behavior [193, 230, 231]. In the previous chapters, mesocorticolimbic and associated networks and their alterations were already described as pivotal for the development of social avoidance. During rewarding social behavior, dopamine sent from the VTA to the NAc acts prosocial [168]. Upstream of the VTA and regulating its excitatory level, OXT neurons in the paraventricular nucleus $(\mathrm{PVN})$ of the hypothalamus increase activity during social interaction and thus enhance sociability. In contrast, inhibition of OXT signaling in the VTA reduced social preference in mice and hamsters [232-234]. Downstream of the VTA, local inhibition or deletion of presynaptic OXT receptors (OXT-R) in the NAc abolished social preference. To add to the regulatory effects of OXT within different brain circuitries, serotonergic cells in the DRN that project to the NAc are also equipped with presynaptic OXT-R and their local inhibition abolished social preference [232]. These findings underline the role of intact local serotonin signaling for prevention of social avoidance, pointed out in the following section, in concert with the actions of OXT in mesolimbic areas. Although the amygdala also contains OXT-R and is involved in both social and anxiety behavior, local antagonism did not change baseline or stressmediated disrupted social behavior [235]. In a model of male adolescent social instability, increased OXT-R density was 
found in the NAc and dorsolateral septum (dIS) [236] and systemic treatment with an OXT-R antagonist increased stress-induced social avoidance [237]. After social fear conditioning, OXT-R binding was also increased in the dorsolateral septum, amygdala and parts of the hippocampus and injection of OXT into the dlS restored social behavior [238]. In contrast to the previous findings, OXT-R overexpression in the dlS promoted avoidance of an aggressor after social defeat whereas local knockdown of the receptor prevented the formation of this aversive social behavior that relies of formation of social memories [239]. This demonstrates how the avoidance-modulating effects of endogenous and exogenous oxytocin depend not only on context but also the anatomic effector sites. Similar to the effects in the mesolimbic network, non-region specific intracerebroventricular (i.c.v.) infusion of an OXT-R antagonist or its systemic administration decreased social preference and interaction in rats and mice $[232,240,241]$ and even evoked strong social avoidance in the latter [235]. In the same study, avoidance towards an aggressor could be prevented by i.c.v. administration of OXT even resulting in social preference towards the former defeater showing its prosocial potential. OXT effects do not only depend on the target region or application method but also sex. Social avoidance could be induced by local infusion of an OXT-R antagonist into the BNST in socially defeated adult female mice but not males [240, 241] and modulation of social behavior by OXT-R agonism and antagonism was demonstrated to be simultaneously dose- and sex-dependent in hamsters [242]. Intranasal OXT reduced social interaction in females in one study [240] but led to increased conditioned social preference in females but not males in another [243]. Different treatment and test protocols might, in part, also account for the different effects as a dose-dependency of systemically applied OXT for social behavior outcomes was clearly demonstrated in mice [244]. Taken together, the data on OXT-mediated modulation of social interaction in socially challenged or even stressed animals is mixed and seems to depend highly on context, age, or sex of the individual - congruent to the pool of data in humans.

\section{Dopamine and BDNF}

With a focus on the mesocorticolimbic network, motivation for social behavior is promoted or inhibited by tuning the dopaminergic activity of the VTA and its projections, which is tightly connected to BDNF signaling, a strong regulator of neuronal plasticity [245]. As the hub of the social reward network, specifically the VTA-NAc (but not VTA-mPFC) pathway acts pro-social via D1-receptor signaling in the NAc [168]. In acute and chronic stress paradigms, avoidant behavior is mediated by both increased dopamine [173, 246] and BDNF signaling [172] within the NAc, yet social withdrawal after chronic stressors seem to rely strongly on
BDNF [173]. Interestingly, activation of dopaminergic signaling in the NAc in naïve California mice induced social avoidance in females but not males whereas defeat-induced avoidance could be reversed by dopamine antagonism in the NAc only in males [246]. Enhanced dopaminergic signaling via D2 but not D1 receptors within the NAc was revealed to facilitate avoidant behavior [247]. Hyperactive dopaminergic VTA neurons induce the upregulation of BDNF and its downstream cascades (i.e., PI3K/Akt, ERK1/2, Gsk-3ß) $[169,174]$ and Gadd45b, a mediator of DNA methylation [248]. In line with this, inhibition of ERK signaling [169] or Gadd45b function [248] normalized avoidant behavior. Direct, local deletion of the BDNF gene in the VTA, as well as local inhibition of the BDNF receptor Tropomyosin receptor kinase B (TrkB) in the NAc prior to social stress, prevents the development of avoidance [172-174]. Conversely, bilateral BDNF infusion into the NAc enhanced susceptibility for social avoidance [169]. Together, this is demonstrating BDNF- and experience-dependent plasticity necessary for abnormal social behavior. The NAc response to VTA activation is locally regulated via the hypothalamicborne neuropeptide CRH. Local antagonism of the $\mathrm{CRH}$ receptors in the NAc prevented the rise of BDNF-levels and thus social avoidance [172]. Of note, systemic TrkB agonism reduced whereas antagonism promoted social avoidance in defeated mice [249]. In line with this, mice with decreased BDNF signaling via dysfunctional TrkB receptor showed intensified and prolonged social avoidance [250]. This points at the translational challenge of how acute vs. chronic, local vs. global alteration of BDNF-TrkB signaling affects affective behavior $[251,252]$ due to the various effector sites and circuits of BDNF action. For instance, BDNF levels were found reduced in frontal cortex, hippocampus, and hypothalamus of avoidant animals [221]. In line with this, increased hippocampal BDNF signaling is capable of preventing social withdrawal whereas its local inhibition promotes it [253, 254]. The SNP Val66Met, which reduces activity-dependent neuronal BDNF release in humans [255] and in transgenic mice [256], protected mice from the development of social avoidance after CSDS. Surprisingly, excitability of VTA neurons was not different compared to wildtypes, but NAc of the homozygous Val66Met mice contained 50\% less BDNF, underlining its local relevance for regulating social interaction [169].

As described in detail in the previous sections, hyperactive VTA-NAc dopaminergic projections are a key feature underlying avoidance behavior after psychosocial stressors. In contrast, mesocortical VTA-mPFC projections are hypoactive [167] with a consecutively marked reduction of dopamine turnover in the frontal cortex $[257,258]$ and DRN. Lowered frontal dopaminergic signaling appears to be specific for the socially avoidant phenotype since it was not altered in a chronic stress model that induced general anxiety 
but no social withdrawal [257]. Moreover, an acute defeat protocol that did not induce social avoidance led to increased prefrontal dopamine as a possible protective factor, whereas chronic defeat inhibited dopaminergic signaling in the $\mathrm{mPFC}$ via prostaglandins and thus enabled the development of social avoidance [258]. The dopamine receptor D1 was found downregulated in the mPFC of avoidant mice, and its local knockdown also promoted avoidance behavior [259]. The amygdala receives mesolimbic dopaminergic inputs that regulate social behavior. In prairie voles, increased dopamine signaling within the amygdala via the D1 receptors (but not D2 subtype) was shown to mediate social avoidance in response to repeated social defeat but interestingly also in stress-naïve voles [260]. Hence, the role of dopaminergic signaling in social avoidance is highly dependent on localization within the circuitry.

The actions of the circuitry eventually leading to socially avoidant behavior are in large parts connected by glucocorticoid, BDNF, and dopamine signaling and are summarized in Fig. 2.

\section{Serotonin}

The serotonergic system with its main source in neurons of the dorsal raphe nuclei (DRN) is a modulator of

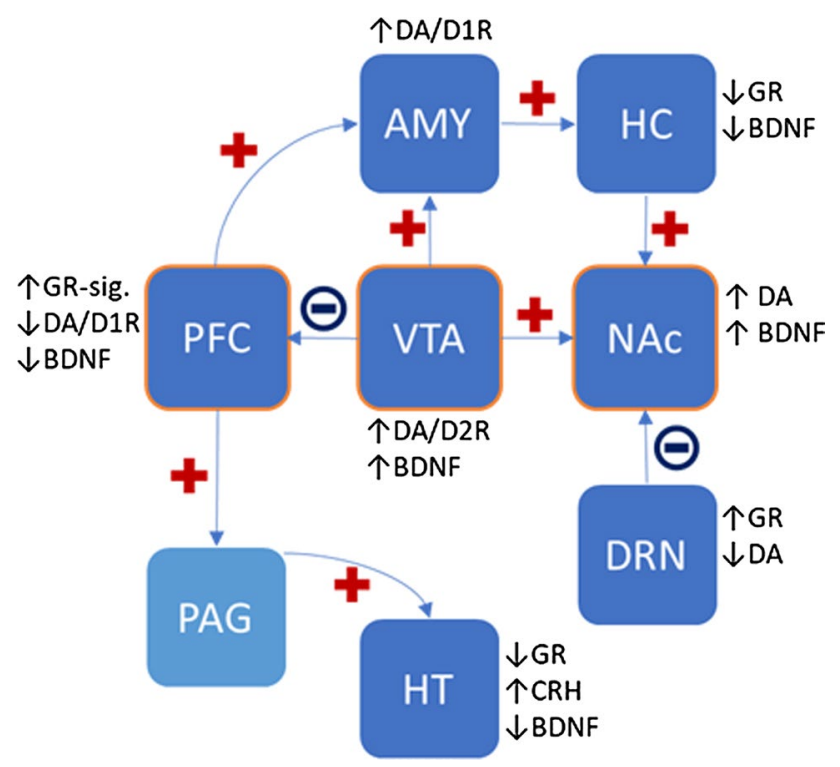

Fig. 2 Alterations of circuitry and main findings of glucocorticoid/ dopamine/BDNF signaling in socially avoidant animals. The mesocorticolimbic system consisting of VTA, PFC, and NAc is in the center of regulating stress-induced social avoidance in preclinical models. Projections with either activity-increase (plus) or -decrease (minus) determine the level of transmitter-release and expression of other modulators and their receptors in the target region (position of arrowhead). $B D N F$ brain-derived neurotrophic factor, $C R H$ corticotropin-releasing hormone, $D 1 R$ and $D 2 R$ dopamine receptor 1 and 2, $D A$ dopamine, $G R$ glucocorticoid receptor) socio-affective, in part GR-driven response independent of the classic HPA axis feedback loop. Treatment of socially avoidant mice with imipramine not only restored social behavior [174] but also downregulated HDAC6, a cytoplasmic lysine deacetylase. HDAC6 modulates hormone- and stress-induced GR translocation, in the dorsal raphe nucleus (DRN). Deletion of HDAC6 in serotonergic neurons of the DRN has been demonstrated to exert antidepressant, anxiolytic effects [261], prevented stress-induced social avoidance together with linked specific morphological alterations and hypoexcitability of the serotonergic cells and translocation of the GR despite elevated plasma CORT [217]. This underlines the importance of raphe circuit homeostasis which ultimately regulates the serotonergic tone of the brain. Serotonergic neurons of the DRN are also linked to the endogenous opioid system in regulating social avoidance. Inhibition of the p38alphaMAPK pathway in serotonergic neurons activated via the dynorphin/kappa opioid receptor (KOR) efficiently blocked the development of social avoidance [262]. The serotonergic tone of the brain, concerted via the DRN and regulated via the serotonin transporter (5-HTT), also modulates vulnerability towards stress-induced social avoidance. A 50\% reduction of 5-HTT expression increased vulnerability without alteration of plasma corticosterone but lowered serotonin turnover in the frontal cortex [263]. In contrast, rodents and primates with a higher baseline concentration of 5HT in brain and plasma showed higher vulnerability to developing social avoidance in a socially crowded environment but failed to produce elevated CORT levels in response to the social stress found in non-avoidant conspecifics [264]. In line with this, acute treatment with the serotonin reuptake inhibitor (SSRI) Citalopram, which facilitates 5-HT transmission in the brain, has been shown to decrease social interaction in rodents [265]. In addition, transiently suppressed 5-HT1A receptor expression in the DNR during early postnatal development which disinhibits serotonergic neurons, leads to higher vulnerability to early life stress and reduced sociability in later life stages in general [266]. This shows, how balanced 5HT metabolism and signaling is a prerequisite for coping with (stressful) social situations and prevention of social avoidance.

\section{Endocannabinoids}

The ECS and especially the CB1 receptor regulate behavior and stress-responses in rodents [142]. Mice genetically deficient for the $\mathrm{CB} 1$ receptor $\left(\mathrm{Cnr1}^{-/-}\right)$show phenotypes similar to clinical symptoms of anxiety and depressive disorders [267] and show certain differences in social behavior. For example, $\mathrm{Cnr}^{-/-}$mice show increased aggressive behavior when confronted with an intruder in their home cage [268, 269], while showing decreased social interaction in a novel environment [269], suggesting context- and stress-dependent 
regulation of social behavior by CB1 signaling. These findings are supported by a study demonstrating increased arousal/anxiety-like behavior in male $\mathrm{Cnr}^{-/-}$mice when exposed to a novel conspecific, which possibly contributes to enhanced social memory/discrimination in these mice [270].

CB1 signaling particularly affects social relationships between mothers and their offspring. Cnr1-/- dams show deficits in maternal care (pup retrieval), which is likely caused by their increased anxiety state and correlated with reduced oxytocin receptor and BDNF expression in the hippocampus [271]. Many of the behavioral phenotypes of Cnr1-/- mice, including increased anxiety and maternal care deficits, are also observed in mice deficient for DAGLa, the main enzyme responsible for 2-AG production in the CNS. These mice, however, did not show a phenotype in a social preference test [272].

Another aspect of social behavior regulated by endocannabinoid signaling is adolescent social play, which is critical for developing social competence in most mammalian species and shows clear sex-differences [273]. Social play behavior is a highly rewarding activity and the ECS is well known for modulating or interacting with neural systems involved in natural rewards, such as the opioid and dopaminergic system [274]. Generally, increasing endocannabinoid tone (e.g. by inhibiting endocannabinoid-degrading enzymes) increases social play behavior in rats, while blocking CB1 receptors reduces it [275-279]. It was further demonstrated that the masculinisation of social play (i.e. increased frequency and duration of play fighting) in juvenile rats is critically dependent on CB1/CB2 signaling [280]. Here, the treatment of neonatal rats with $\mathrm{CB} 1 / \mathrm{CB} 2$ agonists masculinized social play behavior in female rats, while antagonist treatment feminized social play in male rats. Mechanistically, the endocannabinoid-mediated masculinization of social play behavior is possibly related to altered neuron-glia interaction in the amygdala [281]. In perinatal male rats, androgens cause an increase in endocannabinoid tone in the developing amygdala, promoting phagocytosis of newborn cells by microglia. This reduces the number of astrocytes that survive into adolescence, which in turn increases neuronal excitation during social play in male rats.

Next to the amygdala, other brain regions implicated in endocannabinoid effects on social behavior are the ventral hippocampus (vHPC), NAc, and VTA. In mice, social avoidance can be induced by optogenetic activation of BLA-NAc glutamatergic circuits, which could be prevented by systemically increasing 2-AG levels [282]. Furthermore, activation of $\mathrm{CB} 1$ receptors in the vHPC was shown to increase the firing of DA neurons in the VTA and neurons in the NAc shell, thereby disrupting normal social behavior and social recognition [283, 284]. These findings demonstrate regionand circuit-specific effects of endocannabinoid signaling on social behavior.
Finally, the ECS is critically involved in regulating stress responses and several studies have demonstrated a role for endocannabinoid signaling in the effects of stress on social behavior. In a model of PTSD, pre-treatment with cannabinoid agonists or FAAH inhibitors could prevent deficits in social recognition memory, as well as anxiety- and depressive-like behavior induced by a shocking reminder [285]. Similarly, inhibiting 2-AG degradation during SDS could prevent the development of social avoidance [286]. Oppositely, mice that lack DAGLa or CB1 receptors constitutively or on specific neuronal subpopulations are especially sensitive to the behavioral consequences of social stress [287, 288].

A summary of the modulators and their actions in social avoidance (induction or prevention) of animals is shown in Table 3.

\section{Challenges for future translational research on social avoidance}

In the previous sections, social avoidance has been described and reflected from the viewpoints of human and animal studies as a primarily active withdrawal from social interaction, which can be a physiological, adaptive, and protective reaction to social threat and unpleasant social experience. However, social avoidance is not always fear-driven, but can also result from a decreased need for social interactions and thus be a passive trait [40] which was not focused in this review. Hence, a comparison of these two sides of social avoidance and their mechanisms might also be of interest in the future in understanding their role in disease and how to treat them.

The borderline between an active adaptive or maladaptive response is stepless and even more difficult to define when comparing human and animal behavior. Humans can be subjected to both multimodal self-reporting and investigator-based assessments regarding their behavior, underlying emotions, and cognitions whereas assessment in the most common studies of animal species, rodents, relies on careful observation and measuring. Theory of mind, the ability to take the perspective of others, is a key prerequisite for human social cognition although a recent review summons aspects of a theory of mind also in non-human species like apes, dogs, and some birds [289]. Data on social perspective taking or metacognition in rodents are scarce but has been reported in rats [290, 291]. The settings in which social behavior can be probed determines its translational value in both directions. Social stressors resembling acute and chronic physical and psychological abuse and helplessness in different life stages can be modeled in animals and often bear striking resemblance to human negative social experience. Nevertheless, there are also gaps between species that remain harder to bridge as, for example, humans can be subjected to and fear socially evaluative threats and express 
Table 3 Modulators of social avoidance in animals

\begin{tabular}{|c|c|c|}
\hline Modulator & Regulation pro social avoidance & Regulation contra social avoidance \\
\hline Glucocorticoids and HPA axis & $\begin{array}{l}\downarrow \text { CORT (juvenile), specific } \\
\uparrow \text { CORT (adult), non-specific } \\
\uparrow \text { CRH in HT } \\
\downarrow \text { GR in HT and HPC } \\
\uparrow \text { GR-signaling in mPFC } \\
\text { Systemic CORT application (adult) }\end{array}$ & $\begin{array}{l}\text { Systemic CORT application (juvenile) } \\
\text { Systemic inhibition of the GR (adult) } \\
\text { Imipramine: } \downarrow \text { CRH in HT } \\
\text { Escitalopram: } \downarrow \text { CORT, } \uparrow \text { GR in HPC } \\
\text { Icariin: } \downarrow \text { CRH in HT, } \uparrow \text { GR in HPC }\end{array}$ \\
\hline Testosterone & $\downarrow$ testosterone (males only)? & $\downarrow$ vHPC-NAc activity via testosterone? \\
\hline $\mathrm{BDNF}$ & $\begin{array}{l}\uparrow \text { BDNF in NAc and/or VTA } \\
\downarrow \text { BDNF in FC, HPC, HT } \\
\text { Local infusion of BDNF in NAc } \\
\text { Increase of BDNF-signaling in HPC } \\
\text { Systemic TrkB antagonism }\end{array}$ & $\begin{array}{l}\downarrow \text { BDNF in NAc and/or VTA } \\
\text { Inhibition of TrkB signaling in NAc and/or VTA } \\
\text { Inhibition of CRH-receptors in NAc by preven- } \\
\text { tion of BDNF-increase } \\
\text { Increase of BDNF-signaling in HPC } \\
\text { Systemic TrkB agonism } \\
\text { SNP Val66Met with } \downarrow \text { BDNF in NAc }\end{array}$ \\
\hline Dopamine & $\begin{array}{l}\uparrow \text { in VTA and NAc (via D2 receptors) } \\
\downarrow \text { in mPFC and DRN } \\
\downarrow \text { D1 receptor in mPFC } \\
\uparrow \text { DA-signaling via D1 in AMY } \\
\text { knock-out of D1 receptor in mPFC }\end{array}$ & DA antagonism in NAc (males) \\
\hline $5-\mathrm{HT}$ & $\begin{array}{l}\uparrow 5 \text {-HT in brain and plasma } \\
50 \% \text { reduced expression of 5-HTT } \\
\downarrow 5 \mathrm{HT} \text { in the frontal cortex } \\
\downarrow 5 \text {-HT1A receptor expression and disinhibition of } \\
5 \text {-HT neurons (P14-30) } \\
\text { Citalopram: } \uparrow 5 \text {-HT transmission }\end{array}$ & Imipramine: restores properties of 5-HT neurons \\
\hline Oxytocin & $\begin{array}{l}\uparrow \text { OXT-R density in NAc and dLS } \\
\uparrow \text { OXT-R binding in AMY, HPC, dLS } \\
\text { OXT-R overexpression in dLS } \\
\text { Inhibition of OXT signaling in VTA } \\
\text { Inhibition/deletion of OXT-R in NAc } \\
\text { Inhibition of OXT-R in DNR } \\
\text { OXT-R antagonist in BNST (females) } \\
\text { Intranasal OXT (females) } \\
\text { i.c.v. OXT-R antagonist } \\
\text { Systemic OXT-R antagonist }\end{array}$ & $\begin{array}{l}\text { Local injection of OXT into dLS } \\
\text { Knock-out of OXT-R in dLS } \\
\text { i.c.v. OXT } \\
\text { Intranasal OXT (females) }\end{array}$ \\
\hline Endocannabinoids & $\begin{array}{l}\text { Activation of CB1 in HPC } \\
\text { Inhibition of CB1 signaling } \\
\text { knock-out of DAGLa } \\
\text { knock-out -OUT of CB1 }\end{array}$ & $\begin{array}{l}\text { Systemic increase in } 2-A G \\
\text { Inhibition of } 2-A G \text { degradation }\end{array}$ \\
\hline
\end{tabular}

embarrassment. Similarities in behavioral outcomes were apparent in the grade of generalization of avoidance towards social stimuli (i.e., both happy and angry faces in humans and aggressive and non-aggressive conspecifics in rodents). Despite the higher cortical complexity in humans, similar circuitry for social cognition and impairment has repeatedly been described in rodents with emphasis on oxytocin and relatives [292, 293]. In depth knowledge of circuits and molecular mechanisms relies mostly on the cutting-edge techniques applicable in rodents and can not be simply transferred to other species for technical and ethical reasons. Hence, further exploration of cognitive psychology in rodents in regard to the systems covered in this review and beyond could serve as a valuable additional information source for neurobiological and -physiological research.
Focusing on circuitry and molecular regulation underlying social avoidance, we found high overlap between species in the mesolimbic dopaminergic system, the limbic regions and the prefrontal cortex. This comes with little surprise as the so called social brain and its components have repeatedly been described as highly conserved in mammals both anatomically and functionally [165, 294]. The differences or uncertainties in translating findings "from mouse to man" have been described as hurdles in pinpointing the causes for certain behavior and how to manipulate it. Nevertheless, the modulators of social avoidance covered and suggested in our review - from the more obvious glucocorticoids and oxytocin to the less frequently described endocannabinoid system within this context - offer exciting diagnostic and therapeutic levers. Advances in human and animal (f)MRI 
techniques but also high-resolution optical imaging in even freely behaving rodents offer analyses in more naturalistic settings. Biological sampling surely will remain difficult in comparison between species for example regarding brain tissue but translational options should be examined closer: cerebrospinal fluid is more easily attainable, even repeatedly and can be thoroughly analysed from small amounts due to high-throughput mass-spectrometry together with the more commonly sampled plasma or serum. There are still several challenges lying ahead to understand how effects on brain structure and function can be measured optimally and comparably in both humans and animals.

Acknowledgements R. H. is supported by a German Research Foundation (DFG) grant (HU 1302/11-1), a German-Israel Foundation for Scientific Research \& Development (GIF) grant (I-1428-105.4/2017), and an Else-Kröner-Fresenius-Stiftung (EKFS) grant (2017_A35). A.K.G. is supported by three BONFOR Funding Program grants (20181A-05, 2019-2-07, 2020-5-01).

Funding Open Access funding enabled and organized by Projekt DEAL. The authors report no competing biomedical financial interests or personal affiliations in connection with the content of this manuscript.

Open Access This article is licensed under a Creative Commons Attribution 4.0 International License, which permits use, sharing, adaptation, distribution and reproduction in any medium or format, as long as you give appropriate credit to the original author(s) and the source, provide a link to the Creative Commons licence, and indicate if changes were made. The images or other third party material in this article are included in the article's Creative Commons licence, unless indicated otherwise in a credit line to the material. If material is not included in the article's Creative Commons licence and your intended use is not permitted by statutory regulation or exceeds the permitted use, you will need to obtain permission directly from the copyright holder. To view a copy of this licence, visit http://creativecommons.org/licenses/by/4.0/.

\section{References}

1. Snyder-Mackler N, Burger JR, Gaydosh L et al (2020) Social determinants of health and survival in humans and other animals. Science 80(368):9553. https://doi.org/10.1126/science.aax9553

2. Clark DM, Wells A (1995) A Cognitive Model of Social Phobia. In: Heimberg RG, Liebowitz MR, Hope DA, Schneier FR (eds) Social phobia: Diagnosis, Assessment, and Treatment. The Guilford Press, New York, pp 69-94

3. Rytwinski NK, Fresco DM, Heimberg RG et al (2009) Screening for social anxiety disorder with the self-report version of the Liebowitz Social Anxiety Scale. Depress Anxiety 26:34-38. https://doi.org/10.1002/da.20503

4. Kaldewaij R, Koch SBJ, Volman I et al (2017) On the control of social approach-avoidance behavior: neural and endocrine mechanisms. Curr Top Behav Neurosci 30:275-293. https://doi. org/10.1007/7854_2016_446

5. Roelofs K, Elzinga BM, Rotteveel M (2005) The effects of stressinduced cortisol responses on approach-avoidance behavior. Psychoneuroendocrinology 30:665-677. https://doi.org/10.1016/j. psyneuen.2005.02.008
6. Roelofs K, Minelli A, Mars RB et al (2009) On the neural control of social emotional behavior. Soc Cogn Affect Neurosci 4:50-58. https://doi.org/10.1093/scan/nsn036

7. Chen M, Bargh JA (1999) Consequences of automatic evaluation: immediate behavioral predispositions to approach or avoid the stimulus. Pers Soc Psychol Bull 25:215-224. https://doi. org/10.1177/0146167299025002007

8. Heuer K, Rinck M, Becker ES (2007) Avoidance of emotional facial expressions in social anxiety: The Approach-Avoidance Task. Behav Res Ther 45:2990-3001. https://doi.org/10.1016/j. brat.2007.08.010

9. Roelofs K, Putman P, Schouten S et al (2010) Gaze direction differentially affects avoidance tendencies to happy and angry faces in socially anxious individuals. Behav Res Ther 48:290-294. https://doi.org/10.1016/j.brat.2009.11.008

10. Roelofs K, van Peer J, Berretty E et al (2009) Hypothalamus-pituitary-adrenal axis hyperresponsiveness is associated with increased social avoidance behavior in social phobia. Biol Psychiatry 65:336-343. https://doi.org/10.1016/j.biops ych.2008.08.022

11. Allen AP, Kennedy PJ, Dockray S et al (2017) The Trier social stress test: principles and practice. Neurobiol Stress 6:113126. https://doi.org/10.1016/j.ynstr.2016.11.001

12. Frisch JU, Häusser JA, Mojzisch A (2015) The Trier social stress test as a paradigm to study how people respond to threat in social interactions. Front Psychol 6:14. https://doi. org/10.3389/fpsyg.2015.00014

13. Kirschbaum C, Pirke KM, Hellhammer DH (1993) The 'Trier Social Stress Test'-a tool for investigating psychobiological stress responses in a laboratory setting. Neuropsychobiology 28:76-81. https://doi.org/10.1159/000119004

14. Dickerson SS, Kemeny ME (2004) Acute stressors and cortisol responses: a theoretical integration and synthesis of laboratory research. Psychol Bull 130:355-391. https://doi. org/10.1037/0033-2909.130.3.355

15. Lederbogen F, Kirsch P, Haddad L et al (2011) City living and urban upbringing affect neural social stress processing in humans. Nature 474:498-501. https://doi.org/10.1038/natur e10190

16. Dedovic K, Renwick R, Mahani NK et al (2005) The Montreal Imaging Stress Task: using functional imaging to investigate the effects of perceiving and processing psychosocial stress in the human brain. J Psychiatry Neurosci 30:319-325

17. Schultz J, Willems T, Gädeke M et al (2019) A human subcortical network underlying social avoidance revealed by risky economic choices. Elife 8:e45249. https://doi.org/10.7554/ eLife. 45249

18. Hare TA, Tottenham N, Davidson MC et al (2005) Contributions of amygdala and striatal activity in emotion regulation. Biol Psychiatry 57:624-632. https://doi.org/10.1016/j.biops ych.2004.12.038

19. Kohls G, Perino MT, Taylor JM et al (2013) The nucleus accumbens is involved in both the pursuit of social reward and the avoidance of social punishment. Neuropsychologia 51:2062-2069. https://doi.org/10.1016/j.neuropsychologi a.2013.07.020

20. Ly V, Cools R, Roelofs K (2014) Aversive disinhibition of behavior and striatal signaling in social avoidance. Soc Cogn Affect Neurosci 9:1530-1536. https://doi.org/10.1093/scan/nst145

21. Harari-Dahan O, Bernstein A (2017) Oxytocin attenuates social and non-social avoidance: Re-thinking the social specificity of Oxytocin. Psychoneuroendocrinology 81:105-112. https://doi. org/10.1016/j.psyneuen.2017.04.005

22. Aharon I, Etcoff N, Ariely D et al (2001) Beautiful faces have variable reward value. Neuron 32:537-551. https://doi. org/10.1016/S0896-6273(01)00491-3 
23. Kirlic N, Young J, Aupperle RL (2017) Animal to human translational paradigms relevant for approach avoidance conflict decision making. Behav Res Ther 96:14-29. https://doi. org/10.1016/j.brat.2017.04.010

24. Enter D, Terburg D, Harrewijn A et al (2016) Single dose testosterone administration alleviates gaze avoidance in women with Social Anxiety Disorder. Psychoneuroendocrinology 63:26-33. https://doi.org/10.1016/j.psyneuen.2015.09.008

25. Grumet GW (1983) Eye contact: the core of interpersonal relatedness. Psychiatry 46:172-180. https://doi.org/10.1080/00332 747.1983.11024189

26. Moukheiber A, Rautureau G, Perez-Diaz F et al (2010) Gaze avoidance in social phobia: objective measure and correlates. Behav Res Ther 48:147-151. https://doi.org/10.1016/j. brat.2009.09.012

27. Yu H, Duan Y, Zhou X (2017) Guilt in the eyes: Eye movement and physiological evidence for guilt-induced social avoidance. J Exp Soc Psychol 71:128-137. https://doi.org/10.1016/j. jesp.2017.03.007

28. Morris JS, Frith CD, Perrett DI et al (1996) A differential neural response in the human amygdala to fearful and happy facial expressions. Nature 383:812-815. https://doi. org/10.1038/383812a0

29. Whalen PJ, Shin LM, McInerney SC et al (2001) A functional MRI study of human amygdala responses to facial expressions of fear versus anger. Emotion 1:70-83. https://doi. org/10.1037/1528-3542.1.1.70

30. Vieira JB, Tavares TP, Marsh AA, Mitchell DGV (2017) Emotion and personal space: Neural correlates of approach-avoidance tendencies to different facial expressions as a function of coldhearted psychopathic traits. Hum Brain Mapp 38:14921506. https://doi.org/10.1002/hbm.23467

31. Ewbank MP, Fox E, Calder AJ (2010) The interaction between gaze and facial expression in the amygdala and extended amygdala is modulated by anxiety. Front Hum Neurosci 4:56. https ://doi.org/10.3389/fnhum.2010.00056

32. Inagaki TK, Muscatell KA, Irwin MR et al (2012) Inflammation selectively enhances amygdala activity to socially threatening images. Neuroimage 59:3222-3226. https://doi. org/10.1016/j.neuroimage.2011.10.090

33. Volman I, Roelofs K, Koch S et al (2011) Anterior prefrontal cortex inhibition impairs control over social emotional actions. Curr Biol 21:1766-1770. https://doi.org/10.1016/j. cub.2011.08.050

34. Bramson B, Folloni D, Verhagen L et al (2020) Human lateral Frontal Pole contributes to control over emotional approachavoidance actions. J Neurosci. https://doi.org/10.1523/JNEUR OSCI.2048-19.2020

35. Chang J, Yu R (2019) Hippocampal connectivity in the aftermath of acute social stress. Neurobiol Stress 11:100195. https ://doi.org/10.1016/j.ynstr.2019.100195

36. Delgado MR, Jou RL, LeDoux JE, Phelps EA (2009) Avoiding negative outcomes: tracking the mechanisms of avoidance learning in humans during fear conditioning. Front Behav Neurosci 3:33. https://doi.org/10.3389/neuro.08.033.2009

37. Levita L, Hoskin R, Champi S (2012) Avoidance of harm and anxiety: a role for the nucleus accumbens. Neuroimage 62:189-198. https://doi.org/10.1016/j.neuroimage.2012.04.059

38. Schlund MW, Siegle GJ, Ladouceur CD et al (2010) Nothing to fear? Neural systems supporting avoidance behavior in healthy youths. Neuroimage 52:710-719. https://doi.org/10.1016/j. neuroimage.2010.04.244

39. Amir N, Foa EB, Coles ME (1998) Automatic activation and strategic avoidance of threat-relevant information in social phobia. J Abnorm Psychol 107:285-290. https://doi. org/10.1037/0021-843X.107.2.285
40. Vrtička P, Andersson F, Grandjean D et al (2008) Individual attachment style modulates human amygdala and striatum activation during social appraisal. PLoS ONE 3:e2868. https://doi. org/10.1371/journal.pone.0002868

41. Knutson B, Westdorp A, Kaiser E, Hommer D (2000) fMRI visualization of brain activity during a monetary incentive delay task. Neuroimage 12:20-27. https://doi.org/10.1006/ nimg.2000.0593

42. Knutson B, Adams CM, Fong GW, Hommer D (2001) Anticipation of increasing monetary reward selectively recruits nucleus accumbens. J Neurosci 21:159-159. https://doi.org/10.1523/ JNEUROSCI.21-16-j0002.2001

43. Lin A, Adolphs R, Rangel A (2012) Social and monetary reward learning engage overlapping neural substrates. Soc Cogn Affect Neurosci 7:274-281. https://doi.org/10.1093/scan/nsr006

44. Hari R, Kujala MV (2009) Brain basis of human social interaction: from concepts to brain imaging. Physiol Rev 89:453-479. https://doi.org/10.1152/physrev.00041.2007

45. Pan X, de HamiltonC AF (2018) Why and how to use virtual reality to study human social interaction: The challenges of exploring a new research landscape. Br J Psychol 109:395-417. https://doi. org/10.1111/bjop. 12290

46. Zimmer P, Buttlar B, Halbeisen G et al (2019) Virtually stressed? A refined virtual reality adaptation of the Trier Social Stress Test (TSST) induces robust endocrine responses. Psychoneuroendocrinology 101:186-192. https://doi.org/10.1016/j.psyne uen.2018.11.010

47. Czeszumski A, Eustergerling S, Lang A et al (2020) Hyperscanning: a valid method to study neural inter-brain underpinnings of social interaction. Front Hum Neurosci 14:39. https://doi. org/10.3389/fnhum.2020.00039

48. Bentall RP, Taylor JL (2006) Psychological processes and paranoia: implications for forensic behavioural science. Behav Sci Law 24:277-294. https://doi.org/10.1002/bsl.718

49. Dalrymple KL, Zimmerman M (2008) Screening for social fears and social anxiety disorder in psychiatric outpatients. Compr Psychiatry 49:399-406. https://doi.org/10.1016/j.compp sych.2008.01.009

50. Kessler RC, Berglund P, Demler O et al (2005) Lifetime prevalence and age-of-onset distributions of DSM-IV disorders in the national comorbidity survey replication. Arch Gen Psychiatry 62:593. https://doi.org/10.1001/archpsyc.62.6.593

51. WHO - World Health Organization (2016) Internationale Klassifikation psychischer Störungen, 6, überar. Hogrefe, Bern

52. Stein DJ, Szatmari P, Gaebel W et al (2020) Mental, behavioral and neurodevelopmental disorders in the ICD-11: an international perspective on key changes and controversies. BMC Med 18:21. https://doi.org/10.1186/s12916-020-1495-2

53. American Psychiatric Association (2013) Diagnostic and statistical manual of mental disorders, 5th edn. American Psychiatric Association, Washington, D.C.

54. Hunsley J, Mash EJ (2008) A Guide to Assessments that Work. Oxford University Press, New York, Second edi

55. de Osório F, L, (2012) Instruments for the assessment of social anxiety disorder: Validation studies. World J Psychiatry 2:83. https://doi.org/10.5498/wjp.v2.i5.83

56. Watson D, Friend R (1969) Measurement of social-evaluative anxiety. J Consult Clin Psychol 33:448-457. https://doi. org/10.1037/h0027806

57. Asher M, Aderka IM (2018) Gender differences in social anxiety disorder. J Clin Psychol 74:1730-1741. https://doi.org/10.1002/ jclp. 22624

58. Fehm L, Beesdo K, Jacobi F, Fiedler A (2008) Social anxiety disorder above and below the diagnostic threshold: prevalence, comorbidity and impairment in the general population. 
Soc Psychiatry Psychiatr Epidemiol 43:257-265. https://doi. org/10.1007/s00127-007-0299-4

59. Freeman D, Garety PA, Bebbington PE et al (2005) Psychological investigation of the structure of paranoia in a non-clinical population. Br J Psychiatry 186:427-435. https://doi.org/10.1192/ bjp.186.5.427

60. de la Asuncion J, Docx L, Sabbe B et al (2015) Converging evidence of social avoidant behavior in schizophrenia from two approach-avoidance tasks. J Psychiatr Res 69:135-141. https:// doi.org/10.1016/j.jpsychires.2015.08.008

61. Hansen CF, Torgalsbøen A-K, Melle I, Bell MD (2009) Passive/ apathetic social withdrawal and active social avoidance in schizophrenia. J Nerv Ment Dis 197:274-277. https://doi.org/10.1097/ NMD.0b013e31819dbd36

62. Salzer S, Stefini A, Kronmüller K-T et al (2018) CognitiveBehavioral and psychodynamic therapy in adolescents with social anxiety disorder: a multicenter randomized controlled trial. Psychother Psychosom 87:223-233. https://doi.org/10.1159/00048 8990

63. van Dis EAM, van Veen SC, Hagenaars MA et al (2020) Longterm outcomes of cognitive behavioral therapy for anxiety-related disorders. JAMA Psychiatry 77:265. https://doi.org/10.1001/ jamapsychiatry.2019.3986

64. Williams ES, Manning CE, Eagle AL et al (2020) Androgendependent excitability of mouse ventral hippocampal afferents to nucleus accumbens underlies sex-specific susceptibility to stress. Biol Psychiatry 87:492-501. https://doi.org/10.1016/j. biopsych.2019.08.006

65. Li X, Hou Y, Su Y et al (2020) Efficacy and tolerability of paroxetine in adults with social anxiety disorder. Medicine (Baltimore) 99:e19573. https://doi.org/10.1097/MD.0000000000019573

66. Rose GM, Tadi P (2020) Social Anxiety Disorder. In: StatPearls. StatPearls Publishing, Treasure Island (FL)

67. Mataix-Cols D, Fernández de la Cruz L, Monzani B et al (2017) D-Cycloserine augmentation of exposure-based cognitive behavior therapy for anxiety, obsessive-compulsive, and posttraumatic stress disorders. JAMA Psychiatry 74:501. https://doi. org/10.1001/jamapsychiatry.2016.3955

68. Cesková E, Prikryl R, Kaspárek T, Ondrusová M (2005) Psychopathology and treatment responsiveness of patients with firstepisode schizophrenia. Neuropsychiatr Dis Treat 1:179-185. https://doi.org/10.2147/nedt.1.2.179.61045

69. Ogyu K, Noda Y, Yoshida K et al (2020) Early improvements of individual symptoms as a predictor of treatment response to asenapine in patients with schizophrenia. Neuropsychopharmacol Rep. https://doi.org/10.1002/npr2.12103

70. Bas-Hoogendam JM, Westenberg PM (2020) Imaging the socially-anxious brain: recent advances and future prospects. F1000Research https://doi.org/10.12688/f1000research.21214.1

71. Lai C-H (2020) Task MRI-based functional brain network of anxiety. In: Advances in Experimental Medicine and Biology. pp 3-20

72. Li Y, Meng Y, Yuan M et al (2016) Therapy for adult social anxiety disorder. J Clin Psychiatry 77:e1429-e1438. https://doi. org/10.4088/JCP.15r10226

73. Klumpp H, Fitzgerald JM (2018) Neuroimaging predictors and mechanisms of treatment response in social anxiety disorder: an overview of the amygdala. Curr Psychiatry Rep 20:89. https:// doi.org/10.1007/s11920-018-0948-1

74. Sandman CF, Young KS, Burklund LJ et al (2020) Changes in functional connectivity with cognitive behavioral therapy for social anxiety disorder predict outcomes at follow-up. Behav Res Ther 129:103612. https://doi.org/10.1016/j.brat.2020.103612

75. Talati A, Pantazatos SP, Hirsch J, Schneier F (2015) A pilot study of gray matter volume changes associated with paroxetine treatment and response in social anxiety disorder. Psychiatry
Res Neuroimaging 231:279-285. https://doi.org/10.1016/j.pscyc hresns.2015.01.008

76. Wang X, Cheng B, Luo Q et al (2018) Gray Matter Structural Alterations in Social Anxiety Disorder: A Voxel-Based MetaAnalysis. Front Psychiatry 9:449. https://doi.org/10.3389/fpsyt .2018.00449

77. Gentili C, Cristea IA, Angstadt M et al (2016) Beyond emotions: a meta-analysis of neural response within face processing system in social anxiety. Exp Biol Med 241:225-237. https://doi. org/10.1177/1535370215603514

78. van Peer JM, Roelofs K, Rotteveel M et al (2007) The effects of cortisol administration on approach-avoidance behavior: an event-related potential study. Biol Psychol 76:135-146. https:// doi.org/10.1016/j.biopsycho.2007.07.003

79. van Peer JM, Spinhoven P, van Dijk JG, Roelofs K (2009) Cortisol-induced enhancement of emotional face processing in social phobia depends on symptom severity and motivational context. Biol Psychol 81:123-130. https://doi.org/10.1016/j.biops ycho.2009.03.006

80. Zorn JV, Schür RR, Boks MP et al (2017) Cortisol stress reactivity across psychiatric disorders: A systematic review and meta-analysis. Psychoneuroendocrinology 77:25-36. https:// doi.org/10.1016/j.psyneuen.2016.11.036

81. Zaba M, Kirmeier T, Ionescu IA et al (2015) Identification and characterization of HPA-axis reactivity endophenotypes in a cohort of female PTSD patients. Psychoneuroendocrinology 55:102-115. https://doi.org/10.1016/j.psyneuen.2015.02.005

82. Agorastos A, Pervanidou P, Chrousos GP, Baker DG (2019) Developmental trajectories of early life stress and trauma: a narrative review on neurobiological aspects beyond stress system dysregulation. Front Psychiatry 10:118. https://doi.org/10.3389/ fpsyt.2019.00118

83. Enter D, Spinhoven P, Roelofs K (2014) Alleviating social avoidance: effects of single dose testosterone administration on approach-avoidance action. Horm Behav 65:351-354. https://doi. org/10.1016/j.yhbeh.2014.02.001

84. Terburg D, Syal S, Rosenberger LA et al (2016) Testosterone abolishes implicit subordination in social anxiety. Psychoneuroendocrinology 72:205-211. https://doi.org/10.1016/j.psyne uen.2016.07.203

85. Enter D, Spinhoven P, Roelofs K (2016) Dare to approach: single dose testosterone administration promotes threat approach in patients with social anxiety disorder. Clin Psychol Sci 4:10731079. https://doi.org/10.1177/2167702616631499

86. Hutschemaekers MHM, de Kleine RA, Davis ML et al (2020) Endogenous testosterone levels are predictive of symptom reduction with exposure therapy in social anxiety disorder. Psychoneuroendocrinology 115:104612. https://doi.org/10.1016/j.psyne uen.2020.104612

87. Cremers HR, Roelofs K (2016) Social anxiety disorder: a critical overview of neurocognitive research. Wiley Interdiscip Rev Cogn Sci 7:218-232. https://doi.org/10.1002/wcs. 1390

88. Radke S, Volman I, Mehta P et al (2015) Testosterone biases the amygdala toward social threat approach. Sci Adv 1:e1400074. https://doi.org/10.1126/sciadv.1400074

89. Terburg D, van Honk J (2013) Approach-avoidance versus dominance-submissiveness: a multilevel neural framework on how testosterone promotes social status. Emot Rev 5:296-302. https ://doi.org/10.1177/1754073913477510

90. Volman I, Toni I, Verhagen L, Roelofs K (2011) Endogenous testosterone modulates prefrontal-amygdala connectivity during social emotional behavior. Cereb Cortex 21:2282-2290. https:// doi.org/10.1093/cercor/bhr001

91. Mehta PH, Josephs RA (2010) Testosterone and cortisol jointly regulate dominance: Evidence for a dual-hormone 
hypothesis. Horm Behav 58:898-906. https://doi.org/10.1016/j. yhbeh.2010.08.020

92. Kreuder A-K, Scheele D, Schultz J et al (2020) Common and dissociable effects of oxytocin and lorazepam on the neurocircuitry of fear. Proc Natl Acad Sci U S A. https://doi.org/10.1073/ pnas. 1920147117

93. Spengler FB, Schultz J, Scheele D et al (2017) Kinetics and dose dependency of intranasal oxytocin effects on amygdala reactivity. Biol Psychiatry 82:885-894. https://doi.org/10.1016/j.biops ych.2017.04.015

94. Kosfeld M, Heinrichs M, Zak PJ et al (2005) Oxytocin increases trust in humans. Nature 435:673-676. https://doi.org/10.1038/ nature 03701

95. Striepens N, Kendrick KM, Maier W, Hurlemann R (2011) Prosocial effects of oxytocin and clinical evidence for its therapeutic potential. Front Neuroendocrinol 32:426-450. https://doi. org/10.1016/j.yfrne.2011.07.001

96. Yoon S, Kim Y-K (2020) The role of the oxytocin system in anxiety disorders. In: Advances in Experimental Medicine and Biology. pp 103-120

97. Sack M, Spieler D, Wizelman L et al (2017) Intranasal oxytocin reduces provoked symptoms in female patients with posttraumatic stress disorder despite exerting sympathomimetic and positive chronotropic effects in a randomized controlled trial. BMC Med 15:1-11. https://doi.org/10.1186/s12916-017-0801-0

98. Hurlemann R, Scheele D, Kinfe TM et al (2019) Increased temporal discounting in social anxiety disorder normalizes after oxytocin treatment. Psychother Psychosom 88:55-57. https:// doi.org/10.1159/000495259

99. Ziegler C, Dannlowski U, Bräuer D et al (2015) Oxytocin receptor gene methylation: converging multilevel evidence for a role in social anxiety. Neuropsychopharmacology 40:1528-1538. https ://doi.org/10.1038/npp.2015.2

100. Müller LE, Bertsch K, Bülau K et al (2019) Emotional neglect in childhood shapes social dysfunctioning in adults by influencing the oxytocin and the attachment system: Results from a population-based study. Int J Psychophysiol. https://doi.org/10.1016/j. ijpsycho.2018.05.011

101. Hoge EA, Lawson EA, Metcalf CA et al (2012) Plasma oxytocin immunoreactive products and response to trust in patients with social anxiety disorder. Depress Anxiety 29:924-930. https://doi. org/10.1002/da.21973

102. Cohen D, Shamay-Tsoory SG (2018) Oxytocin regulates social approach. Soc Neurosci 13:680-687. https://doi. org/10.1080/17470919.2017.1418428

103. Guastella AJ, Mitchell PB, Dadds MR (2008) Oxytocin increases gaze to the eye region of human faces. Biol Psychiatry 63:3-5. https://doi.org/10.1016/j.biopsych.2007.06.026

104. Radke S, Roelofs K, de Bruijn ERA (2013) Acting on anger: social anxiety modulates approach-avoidance tendencies after oxytocin administration. Psychol Sci 24:1573-1578. https://doi. org/10.1177/0956797612472682

105. Kirsch P (2005) Oxytocin modulates neural circuitry for social cognition and fear in humans. J Neurosci 25:11489-11493. https ://doi.org/10.1523/JNEUROSCI.3984-05.2005

106. Labuschagne I, Phan KL, Wood A et al (2010) Oxytocin attenuates amygdala reactivity to fear in generalized social anxiety disorder. Neuropsychopharmacology 35:2403-2413. https://doi. org/10.1038/npp.2010.123

107. Dodhia S, Hosanagar A, Fitzgerald DA et al (2014) Modulation of resting-state amygdala-frontal functional connectivity by oxytocin in generalized social anxiety disorder. Neuropsychopharmacology 39:2061-2069. https://doi.org/10.1038/npp.2014.53

108. Gorka SM, Fitzgerald DA, Labuschagne I et al (2015) Oxytocin modulation of amygdala functional connectivity to fearful faces in generalized social anxiety disorder. Neuropsychopharmacology 40:278-286. https://doi.org/10.1038/npp.2014.168

109. Guastella AJ, Howard AL, Dadds MR et al (2009) A randomized controlled trial of intranasal oxytocin as an adjunct to exposure therapy for social anxiety disorder. Psychoneuroendocrinology 34:917-923. https://doi.org/10.1016/j.psyneuen.2009.01.005

110. Fang A, Treadway MT, Hofmann SG (2017) Working hard for oneself or others: Effects of oxytocin on reward motivation in social anxiety disorder. Biol Psychol 127:157-162. https://doi. org/10.1016/j.biopsycho.2017.05.015

111. Labuschagne I, Phan KL, Wood A et al (2012) Medial frontal hyperactivity to sad faces in generalized social anxiety disorder and modulation by oxytocin. Int J Neuropsychopharmacol 15:883-896. https://doi.org/10.1017/S1461145711001489

112. Preckel K, Scheele D, Kendrick KM et al (2014) Oxytocin facilitates social approach behavior in women. Front Behav Neurosci 8:191. https://doi.org/10.3389/fnbeh.2014.00191

113. Scheele D, Striepens N, Güntürkün O et al (2012) Oxytocin modulates social distance between males and females. J Neurosci 32:16074-16079. https://doi.org/10.1523/JNEUR OSCI.2755-12.2012

114. van Honk J, Bos PA, Terburg D et al (2015) Neuroendocrine models of social anxiety disorder. Dialogues Clin Neurosci $17: 287-293$

115. Tiihonen J, Kuikka J, Bergström K et al (1997) Dopamine reuptake site densities in patients with social phobia. Am J Psychiatry 154:239-242. https://doi.org/10.1176/ajp.154.2.239

116. Schneier FR, Liebowitz MR, Abi-Dargham A et al (2000) Low dopamine $\mathrm{D}(2)$ receptor binding potential in social phobia. Am J Psychiatry 157:457-459. https://doi.org/10.1176/appi. ajp.157.3.457

117. Cervenka S, Hedman E, Ikoma Y et al (2012) Changes in dopamine D2-receptor binding are associated to symptom reduction after psychotherapy in social anxiety disorder. Transl Psychiatry 2:e120. https://doi.org/10.1038/tp.2012.40

118. Plavén-Sigray P, Hedman E, Victorsson P et al (2017) Extrastriatal dopamine D2-receptor availability in social anxiety disorder. Eur Neuropsychopharmacol 27:462-469. https://doi. org/10.1016/j.euroneuro.2017.03.007

119. Challis C, Berton O (2015) Top-down control of serotonin systems by the prefrontal cortex: a path toward restored socioemotional function in depression. ACS Chem Neurosci 6:1040-1054. https://doi.org/10.1021/acschemneuro.5b00007

120. Harmer CJ, Shelley NC, Cowen PJ, Goodwin GM (2004) Increased positive versus negative affective perception and memory in healthy volunteers following selective serotonin and norepinephrine reuptake inhibition. Am J Psychiatry 161:12561263. https://doi.org/10.1176/appi.ajp.161.7.1256

121. Murphy SE, Longhitano C, Ayres RE et al (2006) Tryptophan supplementation induces a positive bias in the processing of emotional material in healthy female volunteers. Psychopharmacology 187:121-130. https://doi.org/10.1007/s00213-006-0401-8

122. Robinson OJ, Overstreet C, Allen PS et al (2013) The role of serotonin in the neurocircuitry of negative affective bias: serotonergic modulation of the dorsal medial prefrontal-amygdala "aversive amplification" circuit. Neuroimage 78:217-223. https ://doi.org/10.1016/j.neuroimage.2013.03.075

123. van Veen JF, van Vliet IM, de Rijk RH et al (2009) Tryptophan depletion affects the autonomic stress response in generalized social anxiety disorder. Psychoneuroendocrinology 34:15901594. https://doi.org/10.1016/j.psyneuen.2009.05.007

124. Lanzenberger RR, Mitterhauser M, Spindelegger C et al (2007) Reduced serotonin-1A receptor binding in social anxiety disorder. Biol Psychiatry 61:1081-1089. https://doi.org/10.1016/j. biopsych.2006.05.022 
125. Furmark T, Tillfors M, Garpenstrand H et al (2004) Serotonin transporter polymorphism related to amygdala excitability and symptom severity in patients with social phobia. Neurosci Lett 362:189-192. https://doi.org/10.1016/j.neulet.2004.02.070

126. Hariri AR, Mattay VS, Tessitore A et al (2002) Serotonin transporter genetic variation and the response of the human amygdala. Science 297:400-403. https://doi.org/10.1126/science.1071829

127. Stoltenberg SF, Christ CC, Carlo G (2013) Afraid to help: social anxiety partially mediates the association between 5-HTTLPR triallelic genotype and prosocial behavior. Soc Neurosci 8:400406. https://doi.org/10.1080/17470919.2013.807874

128. Stein MB, Chartier MJ, Kozak MV et al (1998) Genetic linkage to the serotonin transporter protein and 5HT2A receptor genes excluded in generalized social phobia. Psychiatry Res 81:283291. https://doi.org/10.1016/S0165-1781(98)00117-6

129. Hjorth OR, Frick A, Gingnell M et al (2019) Expression and coexpression of serotonin and dopamine transporters in social anxiety disorder: a multitracer positron emission tomography study. Mol Psychiatry. https://doi.org/10.1038/s41380-019-0618-7

130. Duman RS, Monteggia LM (2006) A neurotrophic model for stress-related mood disorders. Biol Psychiatry 59:1116-1127. https://doi.org/10.1016/j.biopsych.2006.02.013

131. Carlson JM, Cha J, Harmon-Jones E et al (2014) Influence of the BDNF genotype on amygdalo-prefrontal white matter microstructure is linked to nonconscious attention bias to threat. Cereb Cortex 24:2249-2257. https://doi.org/10.1093/cercor/bht089

132. Lau JYF, Goldman D, Buzas B et al (2010) BDNF gene polymorphism (Val66Met) predicts amygdala and anterior hippocampus responses to emotional faces in anxious and depressed adolescents. Neuroimage 53:952-961. https://doi.org/10.1016/j.neuro image.2009.11.026

133. de Assis GG, Gasanov EV (2019) BDNF and cortisol integrative system - plasticity vs. degeneration: implications of the Val66Met polymorphism. Front Neuroendocrinol 55:100784. https ://doi.org/10.1016/j.yfrne.2019.100784

134. Colzato LS, Van der Does AJW, Kouwenhoven C et al (2011) BDNF Val66Met polymorphism is associated with higher anticipatory cortisol stress response, anxiety, and alcohol consumption in healthy adults. Psychoneuroendocrinology 36:1562-1569. https://doi.org/10.1016/j.psyneuen.2011.04.010

135. Alexander N, Osinsky R, Schmitz A et al (2010) The BDNF Val66Met polymorphism affects HPA-axis reactivity to acute stress. Psychoneuroendocrinology 35:949-953. https://doi. org/10.1016/j.psyneuen.2009.12.008

136. Shalev I, Lerer E, Israel S et al (2009) BDNF Val66Met polymorphism is associated with HPA axis reactivity to psychological stress characterized by genotype and gender interactions. Psychoneuroendocrinology 34:382-388. https://doi.org/10.1016/j. psyneuen.2008.09.017

137. Lu H-C, Mackie K (2016) An introduction to the endogenous cannabinoid system. Biol Psychiatry 79:516-525. https://doi. org/10.1016/j.biopsych.2015.07.028

138. KANO M, (2014) Control of synaptic function by endocannabinoid-mediated retrograde signaling. Proc Japan Acad Ser B 90:235-250. https://doi.org/10.2183/pjab.90.235

139. Chiurchiù V, Battistini L, Maccarrone M (2015) Endocannabinoid signalling in innate and adaptive immunity. Immunology 144:352-364. https://doi.org/10.1111/imm.12441

140. Simon V, Cota D (2017) Mechanisms in endocrinology: endocannabinoids and metabolism: past, present and future. Eur J Endocrinol 176:R309-R324. https://doi.org/10.1530/EJE-16-1044

141. Mackie K (2005) Distribution of cannabinoid receptors in the central and peripheral nervous system. Cannabinoids. SpringerVerlag, Berlin/Heidelberg, Germany, pp 299-325
142. Rubino T, Zamberletti E, Parolaro D (2015) Endocannabinoids and mental disorders. In: Handbook of experimental pharmacology. Germany, pp 261-283

143. Rinaldi-Carmona M, Barth F, Héaulme M et al (1994) SR141716A, a potent and selective antagonist of the brain cannabinoid receptor. FEBS Lett 350:240-244. https://doi. org/10.1016/0014-5793(94)00773-X

144. Christensen R, Kristensen PK, Bartels EM et al (2007) Efficacy and safety of the weight-loss drug rimonabant: a meta-analysis of randomised trials. Lancet 370:1706-1713. https://doi. org/10.1016/S0140-6736(07)61721-8

145. Aagaard L, Hallgreen CE, Hansen EH (2016) Serious adverse events reported for antiobesity medicines: postmarketing experiences from the EU adverse event reporting system EudraVigilance. Int J Obes 40:1742-1747. https://doi.org/10.1038/ ijo.2016.135

146. Chakrabarti B, Kent L, Suckling J et al (2006) Variations in the human cannabinoid receptor (CNR1) gene modulate striatal responses to happy faces. Eur J Neurosci 23:1944-1948. https:// doi.org/10.1111/j.1460-9568.2006.04697.x

147. Chakrabarti B, Baron-Cohen S (2011) Variation in the human cannabinoid receptor CNR1 gene modulates gaze duration for happy faces. Mol Autism 2:10. https://doi. org/10.1186/2040-2392-2-10

148. Juhasz G, Chase D, Pegg E et al (2009) CNR1 gene is associated with high neuroticism and low agreeableness and interacts with recent negative life events to predict current depressive symptoms. Neuropsychopharmacology 34:2019-2027. https://doi. org/10.1038/npp.2009.19

149. Stahl EA, Breen G, Forstner AJ et al (2019) Genome-wide association study identifies 30 loci associated with bipolar disorder. Nat Genet 51:793-803. https://doi.org/10.1038/s4158 8-019-0397-8

150. Peiró AM, García-Gutiérrez MS, Planelles B et al (2020) Association of cannabinoid receptor genes ( CNR1 and CNR2) polymorphisms and panic disorder. Anxiety Stress Coping 33:256265. https://doi.org/10.1080/10615806.2020.1732358

151. Crippa JA, Guimarães FS, Campos AC, Zuardi AW (2018) Translational investigation of the therapeutic potential of cannabidiol (CBD): toward a new age. Front Immunol 9:2009. https://doi. org/10.3389/fimmu.2018.02009

152. Masataka N (2019) Anxiolytic Effects of repeated cannabidiol treatment in teenagers with social anxiety disorders. Front Psychol 10:2466. https://doi.org/10.3389/fpsyg.2019.02466

153. Crippa JAS, Derenusson GN, Ferrari TB et al (2011) Neural basis of anxiolytic effects of cannabidiol (CBD) in generalized social anxiety disorder: a preliminary report. J Psychopharmacol 25:121-130. https://doi.org/10.1177/0269881110379283

154. Bergamaschi MM, Queiroz RHC, Chagas MHN et al (2011) Cannabidiol reduces the anxiety induced by simulated public speaking in treatment-naïve social phobia patients. Neuropsychopharmacology 36:1219-1226. https://doi.org/10.1038/npp.2011.6

155. Modi ME, Sahin M (2019) A unified circuit for social behavior. Neurobiol Learn Mem. https://doi.org/10.1016/j. nlm.2018.08.010

156. Lee NS, Beery AK (2019) Neural circuits underlying rodent sociality: a comparative approach. in: brain imaging in behavioral neuroscience. pp 211-238

157. Toth I, Neumann ID (2013) Animal models of social avoidance and social fear. Cell Tissue Res 354:107-118. https://doi. org/10.1007/s00441-013-1636-4

158. Norden DM, Trojanowski PJ, Villanueva E et al (2016) Sequential activation of microglia and astrocyte cytokine expression precedes increased iba-1 or GFAP immunoreactivity following systemic immune challenge. Glia 64:300-316. https://doi. org/10.1002/glia.22930 
159. Henry CJ, Huang Y, Wynne A et al (2008) Minocycline attenuates lipopolysaccharide (LPS)-induced neuroinflammation, sickness behavior, and anhedonia. J Neuroinflammation 5:1-14. https ://doi.org/10.1186/1742-2094-5-15

160. Hammels C, Pishva E, De Vry J et al (2015) Defeat stress in rodents: From behavior to molecules. Neurosci Biobehav Rev 59:111-140. https://doi.org/10.1016/j.neubiorev.2015.10.006

161. Pryce CR, Fuchs E (2017) Chronic psychosocial stressors in adulthood: studies in mice, rats and tree shrews. Neurobiol Stress 6:94-103. https://doi.org/10.1016/j.ynstr.2016.10.001

162. Björkqvist $\mathrm{K}$ (2001) Social defeat as a stressor in humans. Physiol Behav 73:435-442. https://doi.org/10.1016/S0031 -9384(01)00490-5

163. Martinez M, Calvo-Torrent A, Pico-Alfonso MA (1998) Social defeat and subordination as models of social stress in laboratory rodents: A review. Aggress Behav 24:241-256. https://doi.org/10.1002/ (sici) 1098-2337(1998)24:4<241:aid-ab1>3.3.co;2-z

164. Nestler EJ, Hyman SE (2010) Animal models of neuropsychiatric disorders. Nat Neurosci 13:1161-1169. https://doi.org/10.1038/ nn. 2647

165. O'Connell LA, Hofmann HA (2011) The Vertebrate mesolimbic reward system and social behavior network: A comparative synthesis. J Comp Neurol 519:3599-3639. https://doi.org/10.1002/ cne. 22735

166. Razzoli M, Andreoli M, Michielin F et al (2011) Increased phasic activity of VTA dopamine neurons in mice 3 weeks after repeated social defeat. Behav Brain Res 218:253-257. https:// doi.org/10.1016/j.bbr.2010.11.050

167. Chaudhury D, Walsh JJ, Friedman AK et al (2013) Rapid regulation of depression-related behaviours by control of midbrain dopamine neurons. Nature 493:532-536. https://doi.org/10.1038/ nature 11713

168. Gunaydin LA, Grosenick L, Finkelstein JC et al (2014) Natural neural projection dynamics underlying social behavior. Cell 157:1535-1551. https://doi.org/10.1016/j.cell.2014.05.017

169. Krishnan V, Han MH, Graham DL et al (2007) Molecular adaptations underlying susceptibility and resistance to social defeat in brain reward regions. Cell 131:391-404. https://doi. org/10.1016/j.cell.2007.09.018

170. Cao J-L, Covington HE, Friedman AK et al (2010) Mesolimbic dopamine neurons in the brain reward circuit mediate susceptibility to social defeat and antidepressant action. J Neurosci 30:16453-16458. https://doi.org/10.1523/JNEUR OSCI.3177-10.2010

171. Friedman AK, Walsh JJ, Juarez B et al (2014) Enhancing depression mechanisms in midbrain dopamine neurons achieves homeostatic resilience. Science 80(344):313-319. https://doi. org/10.1126/science. 1249240

172. Walsh JJ, Friedman AK, Sun $\mathrm{H}$ et al (2014) Stress and CRF gate neural activation of BDNF in the mesolimbic reward pathway. Nat Neurosci 17:27-29. https://doi.org/10.1038/nn.3591

173. Wook Koo J, Labonté B, Engmann O et al (2016) Essential role of mesolimbic brain-derived neurotrophic factor in chronic social stress-induced depressive behaviors. Biol Psychiatry 80:469478. https://doi.org/10.1016/j.biopsych.2015.12.009

174. Berton O, McClung CA, DiLeone RJ et al (2006) Essential role of BDNF in the mesolimbic dopamine pathway in social defeat stress. Science 80(311):864-868. https://doi.org/10.1126/scien ce. 1120972

175. Golden SA, Christoffel DJ, Hodes GE et al (2013) Epigenetic regulation of synaptic remodeling in stress disorders. Nat Med 19:337-344. https://doi.org/10.1038/nm.3090.Epigenetic

176. Vialou V, Bagot RC, Cahill ME et al (2014) Prefrontal cortical circuit for depression- and anxiety-related behaviors mediated by cholecystokinin: role of FosB. J Neurosci 34:3878-3887. https:// doi.org/10.1523/JNEUROSCI.1787-13.2014

177. Covington HE, Lobo MK, Maze I et al (2010) Antidepressant effect of optogenetic stimulation of the medial prefrontal cortex. J Neurosci 30:16082-16090. https://doi.org/10.1523/JNEUR OSCI.1731-10.2010

178. Stack A, Carrier N, Dietz D et al (2010) Sex differences in social interaction in rats: role of the immediate-early gene zif268. Neuropsychopharmacology 35:570-580. https://doi.org/10.1038/ npp. 2009.163

179. Gallopin T, Geoffroy H, Rossier J, Lambolez B (2006) Cortical sources of $\mathrm{CRF}, \mathrm{NKB}$, and $\mathrm{CCK}$ and their effects on pyramidal cells in the neocortex. Cereb Cortex 16:1440-1452. https://doi. org/10.1093/cercor/bhj081

180. Bondar N, Bryzgalov L, Ershov N et al (2018) Molecular adaptations to social defeat stress and induced depression in mice. Mol Neurobiol 55:3394-3407. https://doi.org/10.1007/s1203 5-017-0586-3

181. Liu J, Dietz K, Deloyht JM et al (2012) Impaired adult myelination in the prefrontal cortex of socially isolated mice. Nat Neurosci 15:1621-1623. https://doi.org/10.1038/nn.3263

182. Bonnefil V, Dietz K, Amatruda M et al (2019) Region-specific myelin differences define behavioral consequences of chronic social defeat stress in mice. Elife 8:1-13. https://doi.org/10.7554/ eLife. 40855

183. Hagemeyer N, Goebbels S, Papiol S et al (2012) A myelin gene causative of a catatonia-depression syndrome upon aging. EMBO Mol Med 4:528-539. https://doi.org/10.1002/emmm.201200230

184. Cathomas F, Azzinnari D, Bergamini G et al (2019) Oligodendrocyte gene expression is reduced by and influences effects of chronic social stress in mice. Genes Brain Behav 18:1-14. https ://doi.org/10.1111/gbb.12475

185. Kumar S, Hultman R, Hughes D et al (2014) Prefrontal cortex reactivity underlies trait vulnerability to chronic social defeat stress. Nat Commun 5:4537. https://doi.org/10.1038/ncomm s5537

186. Hultman R, Mague SD, Li Q et al (2016) Dysregulation of prefrontal cortex-mediated slow-evolving limbic dynamics drives stress-induced emotional pathology. Neuron 91:439-452. https ://doi.org/10.1016/j.neuron.2016.05.038

187. Dulka BN, Bress KS, Grizzell JA, Cooper MA (2018) Social dominance modulates stress-induced neural activity in medial prefrontal cortex projections to the basolateral amygdala. Neuroscience 388:274-283. https://doi.org/10.1016/j.neuroscien ce.2018.07.042

188. Franklin TB, Silva BA, Perova Z et al (2017) Prefrontal cortical control of a brainstem social behavior circuit. Nat Neurosci 20:260-270. https://doi.org/10.1038/nn.4470

189. Motta SC, Goto M, Gouveia FV et al (2009) Dissecting the brain's fear system reveals the hypothalamus is critical for responding in subordinate conspecific intruders. Proc Natl Acad Sci 106:4870-4875. https://doi.org/10.1073/pnas.0900939106

190. Silva BA, Mattucci C, Krzywkowski P et al (2013) Independent hypothalamic circuits for social and predator fear. Nat Neurosci 16:1731-1733. https://doi.org/10.1038/nn.3573

191. Dong H-W, Petrovich GD, Swanson LW (2001) Topography of projections from amygdala to bed nuclei of the stria terminalis. Brain Res Rev 38:192-246. https://doi.org/10.1016/S0165 -0173(01)00079-0

192. Anacker C, Scholz J, O’Donnell KJ et al (2016) Neuroanatomic differences associated with stress susceptibility and resilience. Biol Psychiatry 79:840-849. https://doi.org/10.1016/j.biops ych.2015.08.009

193. Steinman MQ, Duque-Wilckens N, Trainor BC (2019) Complementary neural circuits for divergent effects of oxytocin: social 
approach versus social anxiety. Biol Psychiatry 85:792-801. https://doi.org/10.1016/j.biopsych.2018.10.008

194. Qi J, Zhang S, Wang HL et al (2014) A glutamatergic reward input from the dorsal raphe to ventral tegmental area dopamine neurons. Nat Commun. https://doi.org/10.1038/ncomms6390

195. Lieberwirth C, Wang Z (2012) The social environment and neurogenesis in the adult mammalian brain. Front Hum Neurosci 6:1-19. https://doi.org/10.3389/fnhum.2012.00118

196. Mouri A, Ukai M, Uchida M et al (2018) Juvenile social defeat stress exposure persistently impairs social behaviors and neurogenesis. Neuropharmacology 133:23-37. https://doi. org/10.1016/j.neuropharm.2018.01.016

197. Wei L, Meaney MJ, Duman RS, Kaffman A (2011) Affiliative behavior requires juvenile, but not adult neurogenesis. $\mathrm{J}$ Neurosci 31:14335-14345. https://doi.org/10.1523/JNEUR OSCI.1333-11.2011

198. Lagace DC, Donovan MH, DeCarolis NA et al (2010) Adult hippocampal neurogenesis is functionally important for stressinduced social avoidance. Proc Natl Acad Sci 107:4436-4441. https://doi.org/10.1073/pnas.0910072107

199. Tse YC, Montoya I, Wong AS et al (2014) A longitudinal study of stress-induced hippocampal volume changes in mice that are susceptible or resilient to chronic social defeat. Hippocampus 24:1120-1128. https://doi.org/10.1002/hipo.22296

200. Okuyama T, Kitamura T, Roy DS et al (2016) Ventral CA1 neurons store social memory. Science 80(353):1536-1541. https://doi.org/10.1126/science.aaf7003

201. Bagot RC, Parise EM, Peña CJ et al (2015) Ventral hippocampal afferents to the nucleus accumbens regulate susceptibility to depression. Nat Commun 6:7062. https://doi.org/10.1038/ ncomms 8062

202. Heidbreder CA, Groenewegen HJ (2003) The medial prefrontal cortex in the rat: Evidence for a dorso-ventral distinction based upon functional and anatomical characteristics. Neurosci Biobehav Rev 27:555-579. https://doi.org/10.1016/j.neubi orev.2003.09.003

203. Wellman LL, Forcelli PA, Aguilar BL, Malkova L (2016) Bidirectional control of social behavior by activity within basolateral and central amygdala of primates. J Neurosci 36:87468756. https://doi.org/10.1523/JNEUROSCI.0333-16.2016

204. Felix-Ortiz AC, Tye KM (2014) Amygdala inputs to the ventral hippocampus bidirectionally modulate social behavior. J Neurosci 34:586-595. https://doi.org/10.1523/JNEUR OSCI.4257-13.2014

205. Wang L, Hou W, He Z et al (2018) Effects of chronic social defeat on social behaviors in adult female mandarin voles (Microtus mandarinus): Involvement of the oxytocin system in the nucleus accumbens. Prog Neuro-Psychopharmacol Biol Psychiatry 82:278-288. https://doi.org/10.1016/j.pnpbp .2017.11.002

206. Jiang X, Lin W, Cheng Y, Wang D (2019) mGluR5 facilitates long-term synaptic depression in a stress-induced depressive mouse model. Can J Psychiatry. https://doi.org/10.1177/07067 43719874162

207. De Kloet ER, Reul JMHM (1987) Feedback action and tonic influence of corticosteroids on brain function: A concept arising from the heterogeneity of brain receptor systems. Psychoneuroendocrinology 12:83-105. https://doi.org/10.1016/03064530(87)90040-0

208. Scheschowitsch K, Leite JA, Assreuy J (2017) New insights in glucocorticoid receptor signaling-more than just a ligand-binding receptor. Front Endocrinol (Lausanne) 8:19-21. https://doi. org/10.3389/fendo.2017.00016

209. Raulo A, Dantzer B (2018) Associations between glucocorticoids and sociality across a continuum of vertebrate social behavior. Ecol Evol 8:7697-7716. https://doi.org/10.1002/ece3.4059
210. Tsigos C, Chrousos GP (2002) Hypothalamic-pituitary-adrenal axis, neuroendocrine factors and stress. J Psychosom Res 53:865-871. https://doi.org/10.1016/S0022-3999(02)00429-4

211. Anacker C, Zunszain PA, Carvalho LA, Pariante CM (2011) The glucocorticoid receptor: Pivot of depression and of antidepressant treatment? Psychoneuroendocrinology 36:415-425. https:// doi.org/10.1016/j.psyneuen.2010.03.007

212. van den Bos E, Tops M, Westenberg PM (2017) Social anxiety and the cortisol response to social evaluation in children and adolescents. Psychoneuroendocrinology 78:159-167. https://doi. org/10.1016/j.psyneuen.2017.02.003

213. Latsko MS, Farnbauch LA, Gilman TL et al (2016) Corticosterone may interact with peripubertal development to shape adult resistance to social defeat. Horm Behav 82:38-45. https://doi. org/10.1016/j.yhbeh.2016.04.009

214. Raineki C, Cortes MR, Belnoue L, Sullivan RM (2012) Effects of early-life abuse differ across development: infant social behavior deficits are followed by adolescent depressive-like behaviors mediated by the amygdala. J Neurosci 32:7758-7765. https://doi. org/10.1523/JNEUROSCI.5843-11.2012

215. Perry RE, Rincón-Cortés M, Braren SH et al (2019) Corticosterone administration targeting a hypo-reactive HPA axis rescues a socially-avoidant phenotype in scarcity-adversity reared rats. Dev Cogn Neurosci 40:100716. https://doi.org/10.1016/j. den.2019.100716

216. Rice GE, Caswell H, Moore P et al (2018) The roles of left versus right anterior temporal lobes in semantic memory: A neuropsychological comparison of postsurgical temporal lobe epilepsy patients. Cereb Cortex 28:1487-1501. https://doi.org/10.1093/ cercor/bhx362

217. Espallergues J, Teegarden SL, Veerakumar A et al (2012) HDAC6 Regulates glucocorticoid receptor signaling in serotonin pathways with critical impact on stress resilience. J Neurosci 32:4400-4416. https://doi.org/10.1523/JNEUR OSCI.5634-11.2012

218. Han Q-Q, Yang L, Huang H-J et al (2017) Differential GR expression and translocation in the hippocampus mediates susceptibility vs. resilience to chronic social defeat stress. Front Neurosci 11:1-10. https://doi.org/10.3389/fnins.2017.00287

219. Elliott E, Ezra-Nevo G, Regev L et al (2010) Resilience to social stress coincides with functional DNA methylation of the Crf gene in adult mice. Nat Neurosci 13:1351-1353. https://doi. org/10.1038/nn.2642

220. Wu X, Wu J, Xia S et al (2013) Icaritin opposes the development of social aversion after defeat stress via increases of GR mRNA and BDNF mRNA in mice. Behav Brain Res 256:602-608. https ://doi.org/10.1016/j.bbr.2013.09.034

221. Berry A, Bellisario V, Capoccia S et al (2012) Social deprivation stress is a triggering factor for the emergence of anxiety- and depression-like behaviours and leads to reduced brain BDNF levels in C57BL/6J mice. Psychoneuroendocrinology 37:762-772. https://doi.org/10.1016/j.psyneuen.2011.09.007

222. Carnevali L, Montano N, Statello R et al (2017) Social stress contagion in rats: Behavioural, autonomic and neuroendocrine correlates. Psychoneuroendocrinology 82:155-163. https://doi. org/10.1016/j.psyneuen.2017.05.017

223. Choleris E, Kavaliers M (1999) Social learning in animals: Sex differences and neurobiological analysis. Pharmacol Biochem Behav 64:767-776. https://doi.org/10.1016/S0091 -3057(99)00141-0

224. Eisenegger C, Haushofer J, Fehr E (2011) The role of testosterone in social interaction. Trends Cogn Sci 15:263-271. https:// doi.org/10.1016/j.tics.2011.04.008

225. Blanchard DC, Sakai RR, McEwen B et al (1993) Subordination stress: Behavioral, brain, and neuroendocrine correlates. 
Behav Brain Res 58:113-121. https://doi.org/10.1016/01664328(93)90096-9

226. Huhman KL, Moore TO, Ferris CF et al (1991) Acute and repeated exposure to social conflict in male golden hamsters: Increases in plasma POMC-peptides and cortisol and decreases in plasma testosterone. Horm Behav 25:206-216. https://doi. org/10.1016/0018-506X(91)90051-I

227. Rose RM, Gordon TP, Bernstein IS (1972) Plasma testosterone levels in the male rhesus: influences of sexual and social stimuli. Science 80(178):643-645. https://doi.org/10.1126/scien ce.178.4061.643

228. Foster MT, Solomon MB, Huhman KL, Bartness TJ (2006) Social defeat increases food intake, body mass, and adiposity in Syrian hamsters. Am J Physiol Integr Comp Physiol 290:R1284R1293. https://doi.org/10.1152/ajpregu.00437.2005

229. Dijkstra H, Tilders FJH, Hiehle MA, Smelik PG (1992) Hormonal reactions to fighting in rat colonies: Prolactin rises during defense, not during offence. Physiol Behav 51:961-968. https:// doi.org/10.1016/0031-9384(92)90078-G

230. Hoyle CHV (1999) Neuropeptide families and their receptors: evolutionary perspectives. Brain Res 848:1-25. https://doi. org/10.1016/S0006-8993(99)01975-7

231. Caldwell HK, Albers HE (2015) Oxytocin, vasopressin, and the motivational forces that drive social behaviors. In: Brain Imaging in Behavioral Neuroscience. pp 51-103

232. Dölen G, Darvishzadeh A, Huang KW, Malenka RC (2013) Social reward requires coordinated activity of nucleus accumbens oxytocin and serotonin. Nature 501:179-184. https://doi. org/10.1038/nature 12518

233. Hung LW, Neuner S, Polepalli JS et al (2017) Gating of social reward by oxytocin in the ventral tegmental area. Science 80(357):1406-1411. https://doi.org/10.1126/science.aan4994

234. Song Z, Borland JM, Larkin TE et al (2016) Activation of oxytocin receptors, but not arginine-vasopressin V1a receptors, in the ventral tegmental area of male Syrian hamsters is essential for the reward-like properties of social interactions. Psychoneuroendocrinology 74:164-172. https://doi.org/10.1016/j.psyne uen.2016.09.001

235. Lukas M, Toth I, Reber SO et al (2011) The neuropeptide oxytocin facilitates pro-social behavior and prevents social avoidance in rats and mice. Neuropsychopharmacology 36:2159-2168. https://doi.org/10.1038/npp.2011.95

236. Hodges TE, Baumbach JL, Marcolin ML et al (2017) Social instability stress in adolescent male rats reduces social interaction and social recognition performance and increases oxytocin receptor binding. Neuroscience 359:172-182. https://doi. org/10.1016/j.neuroscience.2017.07.032

237. Hodges TE, Eltahir AM, Patel S et al (2019) Effects of oxytocin receptor antagonism on social function and corticosterone release after adolescent social instability in male rats. Horm Behav 116:104579. https://doi.org/10.1016/j.yhbeh.2019.104579

238. Zoicas I, Slattery DA, Neumann ID (2014) Brain oxytocin in social fear conditioning and its extinction: involvement of the lateral septum. Neuropsychopharmacology 39:3027-3035. https ://doi.org/10.1038/npp.2014.156

239. Guzmán YF, Tronson NC, Jovasevic V et al (2013) Fear-enhancing effects of septal oxytocin receptors. Nat Neurosci 16:11851187. https://doi.org/10.1038/nn.3465

240. Steinman MQ, Duque-Wilckens N, Greenberg GD et al (2016) Sex-specific effects of stress on oxytocin neurons correspond with responses to intranasal oxytocin. Biol Psychiatry 80:406414. https://doi.org/10.1016/j.biopsych.2015.10.007

241. Duque-Wilckens N, Steinman MQ, Busnelli M et al (2018) Oxytocin receptors in the anteromedial bed nucleus of the stria terminalis promote stress-induced social avoidance in female california mice. Biol Psychiatry 83:203-213. https://doi. org/10.1016/j.biopsych.2017.08.024

242. Borland JM, Aiani LM, Norvelle A et al (2019) Sex-dependent regulation of social reward by oxytocin receptors in the ventral tegmental area. Neuropsychopharmacology 44:785-792. https:// doi.org/10.1038/s41386-018-0262-y

243. Kosaki Y, Watanabe S (2016) Conditioned social preference, but not place preference, produced by intranasal oxytocin in female mice. Behav Neurosci 130:182-195. https://doi.org/10.1037/ bne0000139

244. Kent K, Arientyl V, Khachatryan MM, Wood RI (2013) Oxytocin induces a conditioned social preference in female mice. J Neuroendocrinol 25:803-810. https://doi.org/10.1111/jne.12075

245. Poo M (2001) Neurotrophins as synaptic modulators. Nat Rev Neurosci 2:24-32. https://doi.org/10.1038/35049004

246. Campi KL, Greenberg GD, Kapoor A et al (2014) Sex differences in effects of dopamine D1 receptors on social withdrawal. Neuropharmacology 77:208-216. https://doi.org/10.1016/j.neuro pharm.2013.09.026

247. Francis TC, Chandra R, Friend DM et al (2015) Nucleus accumbens medium spiny neuron subtypes mediate depression-related outcomes to social defeat stress. Biol Psychiatry 77:212-222. https://doi.org/10.1016/j.biopsych.2014.07.021

248. Labonté B, Jeong YH, Parise E et al (2019) Gadd45b mediates depressive-like role through DNA demethylation. Sci Rep 9:1-9. https://doi.org/10.1038/s41598-019-40844-8

249. Rosenhauer AM, Beach LQ, Jeffress EC et al (2019) Brainderived neurotrophic factor signaling mitigates the impact of acute social stress. Neuropharmacology 148:40-49. https://doi. org/10.1016/j.neuropharm.2018.12.016

250. Razzoli M, Domenici E, Carboni L et al (2011) A role for BDNF/ TrkB signaling in behavioral and physiological consequences of social defeat stress. Genes Brain Behav 10:424-433. https://doi. org/10.1111/j.1601-183X.2011.00681.x

251. Martinowich K, Manji H, Lu B (2007) New insights into BDNF function in depression and anxiety. Nat Neurosci 10:1089-1093. https://doi.org/10.1038/nn1971

252. De Vry J, Vanmierlo T, Martínez-Martínez P et al (2016) TrkB in the hippocampus and nucleus accumbens differentially modulates depression-like behavior in mice. Behav Brain Res 296:1525. https://doi.org/10.1016/j.bbr.2015.08.027

253. Duclot F, Kabbaj M (2013) Individual differences in novelty seeking predict subsequent vulnerability to social defeat through a differential epigenetic regulation of brain-derived neurotrophic factor expression. J Neurosci 33:11048-11060. https://doi. org/10.1523/JNEUROSCI.0199-13.2013

254. Ma M, Ren Q, Yang C et al (2016) Adjunctive treatment of brexpiprazole with fluoxetine shows a rapid antidepressant effect in social defeat stress model: Role of BDNF-TrkB signaling. Sci Rep 6:39209. https://doi.org/10.1038/srep39209

255. Egan MF, Kojima M, Callicott JH et al (2003) The BDNF val66 met polymorphism affects activity-dependent secretion of $\mathrm{BDNF}$ and human memory and hippocampal function. Cell 112:257-269. https://doi.org/10.1016/S0092-8674(03)00035-7

256. Chen ZY, Jing D, Bath KG et al (2006) Genetic variant BDNF (Val66Met) polymorphism alters anxiety-related behavior. Science 80(314):140-143. https://doi.org/10.1126/science.1129663

257. Venzala E, García-García AL, Elizalde N, Tordera RM (2013) Social vs. environmental stress models of depression from a behavioural and neurochemical approach. Eur Neuropsychopharmacol 23:697-708. https://doi.org/10.1016/j.euron euro.2012.05.010

258. Tanaka K, Furuyashiki T, Kitaoka S et al (2012) Prostaglandin E2-mediated attenuation of mesocortical dopaminergic pathway is critical for susceptibility to repeated social defeat stress in 
mice. J Neurosci 32:4319-4329. https://doi.org/10.1523/JNEUR OSCI.5952-11.2012

259. Shinohara R, Taniguchi M, Ehrlich AT et al (2018) Dopamine D1 receptor subtype mediates acute stress-induced dendritic growth in excitatory neurons of the medial prefrontal cortex and contributes to suppression of stress susceptibility in mice. Mol Psychiatry 23:1717-1730. https://doi.org/10.1038/mp.2017.177

260. Tickerhoof MC, Hale LH, Butler MJ, Smith AS (2020) Regulation of defeat-induced social avoidance by medial amygdala DRD1 in male and female prairie voles. Psychoneuroendocrinology 113:104542. https://doi.org/10.1016/j.psyneuen.2019.10454 2

261. Fukada M, Hanai A, Nakayama A et al (2012) Loss of deacetylation activity of Hdac6 affects emotional behavior in mice. PLoS ONE. https://doi.org/10.1371/journal.pone.0030924

262. Bruchas MR, Schindler AG, Shankar H et al (2011) Selective p38 $\alpha$ MAPK deletion in serotonergic neurons produces stress resilience in models of depression and addiction. Neuron 71:498-511. https://doi.org/10.1016/j.neuron.2011.06.011

263. Bartolomucci A, Carola V, Pascucci T et al (2010) Increased vulnerability to psychosocial stress in heterozygous serotonin transporter knockout mice. Dis Model Mech 3:459-470. https:// doi.org/10.1242/dmm.004614

264. Lee Y-A, Obora T, Bondonny L et al (2018) The effects of housing density on social interactions and their correlations with serotonin in rodents and primates. Sci Rep 8:3497. https://doi. org/10.1038/s41598-018-21353-6

265. Dekeyne A, Denorme B, Monneyron S, Millan M (2000) Citalopram reduces social interaction in rats by activation of serotonin (5-HT)2C receptors. Neuropharmacology 39:1114-1117. https ://doi.org/10.1016/S0028-3908(99)00268-3

266. Donaldson ZR, Piel DA, Santos TL et al (2014) Developmental effects of serotonin 1A autoreceptors on anxiety and social behavior. Neuropsychopharmacology 39:291-302. https://doi. org/10.1038/npp.2013.185

267. Valverde O, Torrens M (2012) CB1 receptor-deficient mice as a model for depression. Neuroscience 204:193-206. https://doi. org/10.1016/j.neuroscience.2011.09.031

268. Martin M, Ledent C, Parmentier M et al (2002) Involvement of CB1 cannabinoid receptors in emotional behaviour. Psychopharmacology 159:379-387. https://doi.org/10.1007/s0021 3-001-0946-5

269. Haller J, Varga B, Ledent C et al (2004) Context-dependent effects of CB1 cannabinoid gene disruption on anxiety-like and social behaviour in mice. Eur J Neurosci 19:1906-1912. https:// doi.org/10.1111/j.1460-9568.2004.03293.x

270. Litvin Y, Phan A, Hill MN et al (2013) CB 1 receptor signaling regulates social anxiety and memory. Genes, Brain Behav 12:479-489. https://doi.org/10.1111/gbb.12045

271. Schechter M, Weller A, Pittel Z et al (2013) Endocannabinoid receptor deficiency affects maternal care and alters the dam's hippocampal oxytocin receptor and brain-derived neurotrophic factor Expression. J Neuroendocrinol 25:898-909. https://doi. org/10.1111/jne. 12082

272. Jenniches I, Ternes S, Albayram O et al (2016) Anxiety, stress, and fear response in mice with reduced endocannabinoid levels. Biol Psychiatry 79:858-868. https://doi.org/10.1016/j.biops ych.2015.03.033

273. Vanderschuren LJMJ, Achterberg EJM, Trezza V (2016) The neurobiology of social play and its rewarding value in rats. Neurosci Biobehav Rev 70:86-105. https://doi.org/10.1016/j.neubi orev.2016.07.025

274. Wenzel JM, Cheer JF (2018) Endocannabinoid regulation of reward and reinforcement through interaction with dopamine and endogenous opioid signaling. Neuropsychopharmacology 43:103-115. https://doi.org/10.1038/npp.2017.126
275. Trezza V, Damsteegt R, Manduca A et al (2012) Endocannabinoids in amygdala and nucleus accumbens mediate social play reward in adolescent rats. J Neurosci 32:14899-14908. https:// doi.org/10.1523/JNEUROSCI.0114-12.2012

276. Seillier A, Martinez AA, Giuffrida A (2013) Phencyclidineinduced social withdrawal results from deficient stimulation of cannabinoid CB1 receptors: Implications for Schizophrenia. Neuropsychopharmacology 38:1816-1824. https://doi.org/10.1038/ npp.2013.81

277. Schneider P, Pätz M, Spanagel R, Schneider M (2016) Adolescent social rejection alters pain processing in a CB1 receptor dependent manner. Eur Neuropsychopharmacol 26:1201-1212. https://doi.org/10.1016/j.euroneuro.2016.04.007

278. Wei D, Lee D, Li D et al (2016) A role for the endocannabinoid 2-arachidonoyl-sn-glycerol for social and high-fat food reward in male mice. Psychopharmacology 233:1911-1919. https://doi. org/10.1007/s00213-016-4222-0

279. Manduca A, Lassalle O, Sepers $M$ et al (2016) Interacting cannabinoid and opioid receptors in the nucleus accumbens core control adolescent social play. Front Behav Neurosci 10:211. https://doi.org/10.3389/fnbeh.2016.00211

280. Argue KJ, VanRyzin JW, Falvo DJ et al (2017) Activation of both CB1 and CB2 endocannabinoid receptors is critical for masculinization of the developing medial amygdala and juvenile social play behavior. Eneuro. https://doi.org/10.1523/ENEUR O.0344-16.2017

281. VanRyzin JW, Marquardt AE, Argue KJ et al (2019) Microglial phagocytosis of newborn cells is induced by endocannabinoids and sculpts sex differences in juvenile rat social play. Neuron 102:435-449.e6. https://doi.org/10.1016/j.neuron.2019.02.006

282. Folkes OM, Báldi R, Kondev V et al (2020) An endocannabinoid-regulated basolateral amygdala-nucleus accumbens circuit modulates sociability. J Clin Invest 130:1728-1742. https://doi. org/10.1172/JCI131752

283. Loureiro M, Renard J, Zunder J, Laviolette SR (2015) Hippocampal cannabinoid transmission modulates dopamine neuron activity: impact on rewarding memory formation and social interaction. Neuropsychopharmacology 40:1436-1447. https:// doi.org/10.1038/npp.2014.329

284. Loureiro M, Kramar C, Renard J et al (2016) Cannabinoid transmission in the hippocampus activates nucleus accumbens neurons and modulates reward and aversion-related emotional salience. Biol Psychiatry 80:216-225. https://doi.org/10.1016/j. biopsych.2015.10.016

285. Burstein O, Shoshan N, Doron R, Akirav I (2018) Cannabinoids prevent depressive-like symptoms and alterations in BDNF expression in a rat model of PTSD. Prog Neuro-Psychopharmacol Biol Psychiatry 84:129-139. https://doi.org/10.1016/j.pnpbp 2018.01.026

286. Nie X, Kitaoka S, Shinohara M et al (2019) Roles of Toll-like receptor $2 / 4$, monoacylglycerol lipase, and cyclooxygenase in social defeat stress-induced prostaglandin E2 synthesis in the brain and their behavioral relevance. Sci Rep 9:17548. https:// doi.org/10.1038/s41598-019-54082-5

287. Dubreucq S, Kambire S, Conforzi M et al (2012) Cannabinoid type 1 receptors located on single-minded 1-expressing neurons control emotional behaviors. Neuroscience 204:230-244. https ://doi.org/10.1016/j.neuroscience.2011.08.049

288. Dubreucq S, Matias I, Cardinal P et al (2012) Genetic dissection of the role of cannabinoid type- 1 receptors in the emotional consequences of repeated social stress in mice. Neuropsychopharmacology 37:1885-1900. https://doi.org/10.1038/npp.2012.36

289. Krupenye C, Call J (2019) Theory of mind in animals: current and future directions. Wiley Interdiscip Rev Cogn Sci 10:1-25. https://doi.org/10.1002/wcs. 1503 
290. Yuki S, Okanoya K (2017) Rats show adaptive choice in a metacognitive task with high uncertainty. J Exp Psychol Anim Learn Cogn 43:109-118. https://doi.org/10.1037/xan0000130

291. Kozma K, Kassai F, Ernyey AJ, Gyertyán I (2019) Establishment of a rodent cooperation assay as a model of social cognition. $\mathbf{J}$ Pharmacol Toxicol Methods 97:44-51. https://doi.org/10.1016/j. vascn.2019.03.003

292. Donaldson ZR, Young LJ (2008) Oxytocin, vasopressin, and the neurogenetics of sociality. Science 80(322):900-904. https://doi. org/10.1126/science. 1158668
293. Goodson JL (2013) Deconstructing sociality, social evolution and relevant nonapeptide functions. Psychoneuroendocrinology 38:465-478. https://doi.org/10.1016/j.psyneuen.2012.12.005

294. Skuse DH, Gallagher L (2009) Dopaminergic-neuropeptide interactions in the social brain. Trends Cogn Sci 13:27-35. https:// doi.org/10.1016/j.tics.2008.09.007

Publisher's Note Springer Nature remains neutral with regard to jurisdictional claims in published maps and institutional affiliations. 